OPEN ACCESS

Edited by:

Rodney Donlan,

Centers for Disease Control and

Prevention (CDC), United States

Reviewed by:

Arianna Tavanti,

University of Pisa, Italy

David Williams,

Cardiff University, United Kingdom

*Correspondence:

Carolina H. Pohl

PohlCH@ufs.ac.za

Specialty section:

This article was submitted to

Biofilms,

a section of the journal

Frontiers in Cellular and

Infection Microbiology

Received: 15 December 2021

Accepted: 26 January 2022

Published: 18 February 2022

Citation:

Pohl CH (2022) Recent Advances and Opportunities in the Study of Candida albicans Polymicrobial Biofilms.

Front. Cell. Infect. Microbiol. 12:836379.

doi: 10.3389/fcimb.2022.836379

\section{Recent Advances and Opportunities in the Study of Candida albicans Polymicrobial Biofilms}

\author{
Carolina H. Pohl* \\ South African Research Chair Initiative (SARChl) Research Chair in Pathogenic Yeasts, Department of Microbiology and \\ Biochemistry, University of the Free State, Bloemfontein, South Africa
}

It is well known that the opportunistic pathogenic yeast, Candida albicans, can form polymicrobial biofilms with a variety of bacteria, both in vitro and in vivo, and that these polymicrobial biofilms can impact the course and management of disease. Although specific interactions are often described as either synergistic or antagonistic, this may be an oversimplification. Polymicrobial biofilms are complex two-way interacting communities, regulated by inter-domain (inter-kingdom) signaling and various molecular mechanisms. This review article will highlight advances over the last six years (2016-2021) regarding the unique biology of polymicrobial biofilms formed by $C$. albicans and bacteria, including regulation of their formation. In addition, some of the consequences of these interactions, such as the influence of co-existence on antimicrobial susceptibility and virulence, will be discussed. Since the aim of this knowledge is to inform possible alternative treatment options, recent studies on the discovery of novel anti-biofilm compounds will also be included. Throughout, an attempt will be made to identify ongoing challenges in this area.

Keywords: Candida albicans, polymicrobial biofilm, biofilm formation, antimicrobial resistance, treatment options

\section{INTRODUCTION}

The opportunistic pathogenic yeast, Candida albicans can form biofilms on biotic and abiotic surfaces including implanted medical devices (Tsui et al., 2016). These biofilms are also often polymicrobial in nature, containing other fungi (Rossoni et al., 2015; Pathirana et al., 2019), bacteria (Khan et al., 2021) and viruses (Mazaheritehrani et al., 2014; Ascione et al., 2017). The proximity of all these organisms within a biofilm allows for interaction via physical means as well as through secreted compounds, such as quorum sensing molecules, redox active compounds and bioactive lipids (Fourie and Pohl, 2019). In addition, the availability of and competition for nutrients play important roles in the interaction (Trejo-Hernández et al., 2014; Arzmi et al., 2016; Fourie et al., 2018), which is often described as synergistic, competitive or antagonistic (Trejo-Hernández et al., 2014; Delaney et al., 2018; Garcia et al., 2020), although this may be a simplistic view as it is becoming evident that the interaction is complex and bi-directional (Fourie and Pohl, 2019). The outcome of the interaction may also be influenced by various host factors, adding another layer of complexity (Fourie et al., 2016; Negrini et al., 2019; Van Dyck et al., 2021). 
Polymicrobial interactions may influence the expression of virulence factors (Trejo-Hernández et al., 2014; Morse et al., 2019; Farrokhi et al., 2021) and these biofilms are often more resistant to antimicrobial drugs than their monomicrobial counterparts (Ascione et al., 2017; Orazi and O'Toole, 2019; Little et al., 2021). In addition, polymicrobial interactions may also influence the host immune response and the outcome of infection (Bergeron et al., 2017). Thus, understanding these interactions, including the molecular mechanisms of regulation, is important to manage C. albicans-containing polymicrobial biofilms (PMBs).

Since the study of PMBs has gained increasing interest, especially during the last five years, this review will focus on the recent advances in the study of $C$. albicans PMBs, including the regulation and consequences for antimicrobial susceptibility and virulence. Recent work regarding discovery of novel antibiofilm treatment options will be highlighted.

\section{ADVANCES IN MODELS USED TO CHARACTERIZE POLYMICROBIAL BIOFILMS}

In order to study the interaction between C. albicans and bacteria, various biofilm models are used (Gabrilska and Rambaugh, 2015). The different models are important to consider as they may influence the formation and regulation of biofilms, as well as their consequences. This will also impact the comparability of results across the different platforms Stoffel et al., (2020). Common in vitro models used to study C. albicans PMBs include those traditionally used to study single species biofilms and these have recently been reviewed by Chevalier and colleagues (2018). An exciting advance in the development of in vitro models for PMBs, is the $n$ BioChip platform developed by Srinivasan and co-workers (2017). This platform consists of hundreds to thousands of identical nanobiofilms, encapsulated in hydrogel spots. The cells are inoculated into suitable media and combined with cellulose based hydrogels. The cultures are robotically printed onto glass sides using a microarray printer and biofilm allowed to form, which are then scanned using a microarray reader. PMBs of C. albicans and Staphylococcus aureus were formed, and the biofilm morphology characterized. It was found that the PMBs consisted of filamentous $C$. albicans with $S$. aureus microcolonies interspersed in between the hyphae. An advantage of this model is that the biofilms can withstand washing steps common to most assays This facilitates high throughput downstream applications, such as screening for antimicrobial resistance as well as novel antimicrobial drugs. Despite the recent advances, in vitro models most often utilize nutrient rich media or physico-chemical parameters that do not necessarily reflect conditions in the host. During the last five years many models that attempt to better approximate the conditions within a host niche have been developed and improved upon.

One of the host niches that is almost synonymous with biofilms is the oral cavity and several models for PMB formation have recently been developed to more closely approximate the conditions in the host. These models include models that better mimic the availability of nutrients (Montelongo-Jauregui et al., 2016), the oxygen levels present in root canals (Toral et al., 2017; Abusrewil et al., 2020) as well as the various bacteria associated with either caries or soft tissue infection in vitro (Abusrewil et al., 2020; Young et al., 2021). In addition, commercially available organotypic oral mucosal models have been used to study the interaction between $C$. albicans and bacteria (Krishnamoorthy et al., 2020). However, a disadvantage of commercially available mucosal models, identified by Morse and co-workers (2018), is their high purchase costs. These authors developed cost effective threedimensional mucosal models to evaluate the impact of denture associated biofilm infections by mono- and polymicrobial $C$. albicans containing biofilms in terms of tissue damage and indicated the potential of these models to be further developed to closer mimic the host responses. In addition to dentures, other abiotic surfaces (such as titanium used for dental implants) are also relevant to the oral cavity. An in vitro model of C. albicans/ Streptococcus gordonii dual-species biofilms on titanium discs Montelongo-Jauregui et al. (2018) has also been developed. All these models indicated the formation of robust PMBs and synergistic cross-kingdom interactions between C. albicans and oral bacteria, under conditions that may be present in the oral cavity.

Another context in which PMBs are important, is wound infections. Townsend and co-workers (2016) developed a threedimensional wound infection model on complex hydrogel-based cellulose to mimic diabetic foot ulcer PMB infection by $C$. albicans, Pseudomonas aeruginosa and S. aureus. They found that this model allowed the formation of structurally complex biofilms, which had a greater impact on antimicrobial susceptibility, compared to conventional in vitro biofilms.

C. albicans and $P$. aeruginosa PMBs have also been studied extensively in the context of the cystic fibrosis lung [reviewed in (Fourie and Pohl, 2019)]. However, in vitro, these studies do not consider biofilm formation under flow conditions (Kasetty et al., 2021). Kasetty and co-workers (2021) examined the dynamics of polymicrobial interaction using microfluidic devices and found that, contrary to static in vitro biofilm models, the interaction was not antagonistic towards C. albicans, but resulted in increased filamentation of $C$. albicans and increased biofilm biomass accumulation by both species. The impact that $C$. albicans filamentation may have on the formation of PMBs, was demonstrated by Ruiz-Sorribas and colleagues (2021) in an in vitro model of PMBs, containing C. albicans, S. aureus and Escherichia coli. The research used two different RPMI-1640 based media to obtain different levels of C. albicans hyphal formation. Their results indicated that biofilms with more hyphae had larger biomass and resulted in increased expression bacterial virulence-associated genes. In biofilms rich in hyphae, $S$. aureus virulence-associated genes, such as those encoding haemolysin delta ( $h l d)$, haemolysin alpha (hla) and clumping factor A (clfA), were upregulated. Clumping factor A has a role in bacterial adhesion and promotes $S$. aureus colonization of biotic and abiotic surfaces (Herman-Bausier et al., 2018). Similarly, the 
gene encoding poly- $\mathrm{N}$-acetylglucosamine synthase (icaA), responsible for exopolysaccharide synthesis was upregulated in hyphae-rich biofilms compared to hyphae-poor biofilms. This may indicate an increase in EXM production with implications for PMB formation and antimicrobial resistance.

The remaining challenge is that the complex nature of PMBs and the influences exerted on them by various parameters in the different models, currently complicates the comparison of data regarding formation and consequences (e.g. susceptibility to antimicrobial compounds) of PMBs across different studies (Chevalier et al., 2018; Stoffel et al., 2020). An important aspect to take into consideration when designing experiments and comparing data from various sources is the effect of priority (i.e. the order in which microbes are inoculated to form biofilms) (Cheong et al., 2021), as this may drastically influence the structure (and potentially the gene expression) of a biofilm. An example is the recently published study where the interaction between C. albicans and two bacteria, S. aureus and Citrobacter freundii, was investigated. When C. albicans and C. freundii were co-inoculated (neutral priority) or when C. albicans was given priority, the yeast formed hyphal networks, containing very few yeast cells, with $C$. freundii attaching and colonizing the hyphae via mannose-binding lectins. In these biofilms, the proportional abundance of C. albicans increased. The opposite was observed when $C$. freundii had priority, with no hyphae formed, but yeast cell aggregates formed on a dense C. freundii biofilm and decreased proportional abundance of C. albicans. Similar results were seen regarding proportional abundance under the different scenarios for C. albicans and S. aureus. Interestingly, in polymicrobial interactions involving all three organisms, $C$. freundii out-competes $S$. aureus for binding sites on C. albicans.

In addition, although mammalian animal models are probably the most relevant to study C. albicans containing PMBs, it is impractical and unethical to use them in studies that require large numbers of animals, such as high throughput screening of potential anti-biofilm compounds. Here the use of alternative animal models, such as invertebrates (e.g. Caenorhabditis elegans, Drosophila melanogaster and Galleria mellonella) may provide a compromise (Gabrilska and Rambaugh, 2015; Holt et al., 2017; Farrokhi et al., 2021; Fourie et al., 2021; Mochochoko et al., 2021), and possible future endeavors could work to further establish them as PMB infection models. A summary of the PMB models, some advances made by them and possible applications are presented in Figure 1.

\section{INCREASED UNDERSTANDING OF THE COMPLEX INTERACTIONS}

\section{Influence of Environmental and Host Factors}

We have gained an increased appreciation of the complexity of the interaction between $C$. albicans and various bacteria, how the microbes influence each other and how the interactions may be influenced by the host as well as various environmental factors, including nutrient supply, oxygen levels, and the local microbiome (Krüger et al., 2019; Gaston et al., 2021). As expected, the different nutrients as well as their concentrations supplied by different media influenced biofilm architecture, biomass and metabolic activity (Table 1). Toral and coworkers (2017) determined the formation of C. albicansEnterococcus faecalis, C. albicans-S. aureus biofilms as well as biofilms consisting of all three organisms on tooth surfaces under different atmospheric conditions, i.e. aerobic and microaerophilic $\left(10 \% \mathrm{CO}_{2}\right)$. It was found that although there were differences in biofilm formation on the various parts of the tooth, generally the PMBs grew better in the microaerophilic atmosphere. Similarly, when the influence of different atmospheric condition (aerobic, 5\% $\mathrm{CO}_{2}$, and anaerobic - $85 \%$ $\mathrm{N}_{2}, 10 \% \mathrm{CO}_{2}, 5 \% \mathrm{H}_{2}$ ) was evaluated on PMBs consisting of $C$. albicans-S. gordonii-Fusobacterium nucleatum-Porphyromonas gingivalis (Abusrewil et al., 2020), it was found that the greats biofilm formation occurred under $5 \% \mathrm{CO}_{2}$ conditions. This may be due to the ability of both S. gordonii and C. albicans to grow well under this condition.

The presence of host factors such as heme may also influence the interaction in PMBs. Guo and co-workers (2020) found that competition for heme may not only influence $C$. albicans- $P$. gingivalis biofilm biomass, but that it may provide an advantage to the bacterium, increasing its vitality as well as resistance to serum and antibiotics. This advantage may be due to the ability of $P$. gingivalis to increase agglutination of erythrocytes and increasing its expression of heme utilization-related and gingipain expressing genes under low heme conditions. Host behavior, such as the use of nicotine, may also influence PMBs in the oral cavity. In a C. albicans-S. mutans $\mathrm{PMB}$, nicotine caused a dose dependent increase in biofilm formation (CFU/ml as well as EXM production) by both organisms, although high levels of nicotine decreased the C. albicans CFU/ml (Liu et al., 2017).

C. albicans does not only interact with pathogenic bacteria, but also with commensal bacteria and other commensal fungi present in the host microbiome and serve to maintain microbial homeostasis (d'Enfert et al., 2021). Although several researchers have studied the impact of individual (or a few) members of the microbiome on C. albicans (as discussed in this review), the complexity of the microbiome poses challenges in gaining a more complete picture of how all the interactions within the microbiome. A recent example of the influence of a commensal bacterium on a PMB is found in the work of Huffines and Scoffield (2020) who found that the commensal bacterium, Streptococcus parasanguinis, influenced C. albicans-S. mutans $\mathrm{PMB}$ formation. In this context, S. parasanguinis decreased biofilm formation and restricted the incorporation of C. albicans into the PMB. IT also disrupted S. mutans glucose metabolism and caused a decrease in in glucosyltransferase activity and glucan synthesis.

\section{Regulation of the Complex Interaction}

The mechanisms by which C. albicans and bacteria facilitate their interactions have also become clearer, and during the past decade some C. albicans genes were identified that play a role in these interactions. Dutton and co-workers (2016) found that deletion 


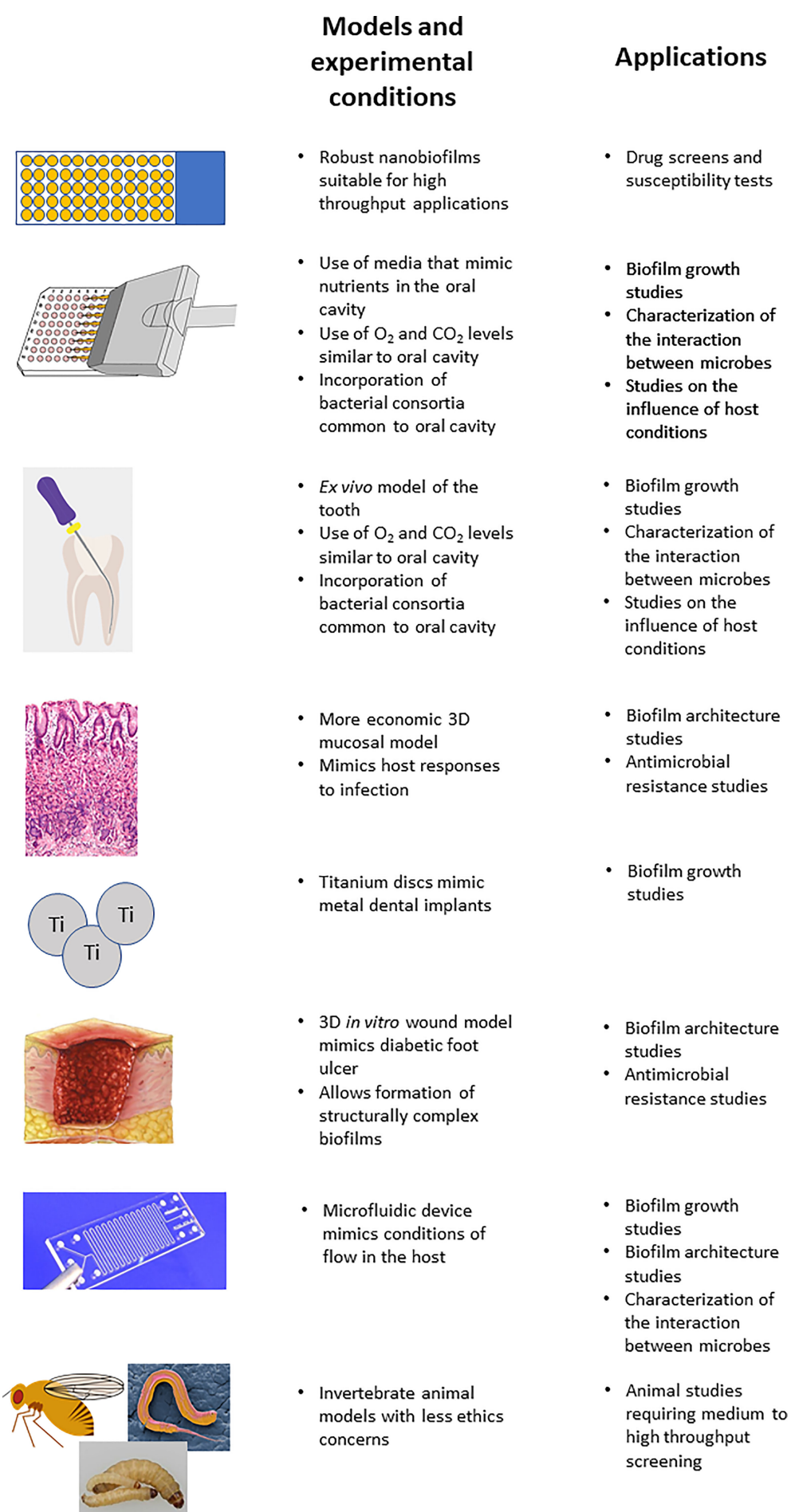

FIGURE 1 | Summary of the models discussed in the study of polymicrobial biofilms.

of SAP9 (encoding a secreted aspartyl protease) caused $C$. albicans to form more compact biofilms and caused a decrease in incorporation of S. gordonii, Streptococcus mutans, Streptococcus oralis, Streptococcus parasanguinis, Streptococcus sanguinis and Enterococcus faecalis into dual species biofilms, suggesting that Sap9 may play a role in regulating the competition between C. albicans and oral bacteria. A possible role for SAP9 as well as ALS3 and HWP1 in the interaction 
TABLE 1 | Summary of the recent studies highlighting the impact of different media on Candida albicans containing polymicrobial biofilms.

\begin{tabular}{|c|c|c|c|}
\hline $\begin{array}{l}\text { Bacteria interacting } \\
\text { with C. albicans }\end{array}$ & Media composition & Influence on polymicrobial biofilm & Reference \\
\hline Actinomyces naeslundii & RMPI-1640 vs Artificial Saliva Medium & $\begin{array}{l}\text { Biomass and metabolic activity were } C \text {. albicans strain } \\
\text { and media specific }\end{array}$ & Arzmi et al. (2016) \\
\hline Streptococcus grodonii & $\begin{array}{l}\text { RPMl-1640, Todd Hewitt Broth }+0.02 \% \text { Yeast Extract, } \\
1: 1 \text { combination, synthetic saliva }\end{array}$ & $\begin{array}{l}\text { Media composition influenced biofilm architecture, } \\
\text { although all enabled synergistic interaction }\end{array}$ & $\begin{array}{l}\text { Montelongo-Jauregui } \\
\text { et al. (2016) }\end{array}$ \\
\hline \multirow[t]{2}{*}{ Streptococcus mutans } & RMPI-1640 vs Artificial Saliva Medium & $\begin{array}{l}\text { Biomass and metabolic activity were C. albicans strain } \\
\text { and media specific }\end{array}$ & $\begin{array}{l}\text { Arzmi et al. (2016); } \\
\text { Brito et al. (2021) }\end{array}$ \\
\hline & Different glucose concentrations & $\begin{array}{l}\text { [Glucose] }>60 \mathrm{mM} \\
\uparrow \text { biofilm biomass } \\
\uparrow C . \text { albicans CFUs/ml } \\
\uparrow \text { Insoluble EPS }\end{array}$ & \\
\hline
\end{tabular}

between $C$. albicans an $P$. gingivalis was also identified (Sztukowska et al., 2018; Bartnika et al., 2019). These genes were significantly upregulated in PMBs, grown under normoxic conditions. These authors further showed that the C. albicans adhesin, Als3, tightly interacts with the cell surface of $P$. gingivalis and that the bacterial gingipains and internalin (InlJ) are involved in this adhesion, although other proteins, such as enolase (Eno1) could also play a role. Als3, and possibly Als1, also mediate the interaction between $C$. albicans and $S$. aureus (Van Dyck et al., 2021). The interaction between C. albicans and Actinomyces viscosus, which is often associated with root caries, is considered synergistic, with greater biomass and EXM produced in these biofilms (Deng et al., 2019a). Deng and coworkers (2019b) identified that ergosterol may play a role in this specific interaction as C. albicans erg11 $/ \Delta$ strains did not form enhanced biofilm biomass in PMBs. Another gene, involved in $C$. albicans biofilm formation and interaction with bacteria, is SET3 (encoding a component of the Set3/Hos2 histone deacetylase complex) (Fourie et al., 2021). This gene was found to play a role during early C. albicans-P. aeruginosa biofilm formation as well as the virulence of mono- and polymicrobial infection in $C$. elegans, although the molecular mechanisms behind this regulation is still unknown.

$\mathrm{Xu}$ and co-workers (2017) identified one of the six known master regulators (Bcr1, Brg1, Efg1, Tec1, Ndt80 and Rob 1) of filamentation in C. albicans, Efg1, as important in the interaction between the yeast and $S$. oralis. EFG1 was the only master regulator encoding gene that was upregulated in the presence of S. oralis in in vitro biofilms, organotypic oral mucosal models and on the tongue of orally infected mice. These authors also identified a downstream effector, Als1, (but not Als3 or Hwp1) that operated in concert with Efg1 in mediating the C. albicans-S. oralis interaction. Similarly, during the interaction between C. albicans and $S$. gordonii, mutants of three of the six master regulators (Brg1, Efg1 and Tec1), together with other regulators responsible for filamentation in C. albicans (Sfl1, Tup1 and Rim101) formed reduced biofilms with S. gordonii (Chinnici et al., 2019) and the authors speculated that this indicated that C. albicans filamentation was crucial for the development of robust PMBs. These authors also found that regulators involved in cell wall integrity and adhesion (Leu3, Cta4, Cas5 and Sko1) were negative regulators of C. albicans-S. gordonii biofilms. However, a study by Montelongo-Jauregui and co-workers (2019) challenged the idea that $C$. albicans hyphal formation and adherence are required for its interaction with $S$. gordonii in dual-species biofilms. They showed that $C$. albicans mutants $(e f g 1 \Delta / \Delta$ and $\operatorname{brg} 1 \Delta / \Delta)$, which are unable to filament and had biofilm formation defects, could form robust dual-species biofilms, with S. gordonii adhering to the yeast cells. These authors also showed that $S$. gordonii could form dual-species biofilms with an als $3 \Delta / \Delta$ mutant when the two were co-inoculated in synthetic saliva medium. This lack of Als3 requirement was confirmed using a $b c r 1 \Delta / \Delta$ mutant, which does not express any of the Als adhesins, and point to the existence of other adhesive interactions that may be important in PMB formation. Interestingly, a study by Wan and co-workers (2021) found that the binding force between C. albicans and S. gordonii is approximately 2 -fold higher than that between $C$. albicans and $S$. mutans. These interactions may also depend on the enhanced production of EXM by PMB (Montelongo-Jauregui et al., 2019) and specific nanostructures, such as C. albicans-produced nanofibrils (Veerapandian and Vediyappan, 2019).

Some of these surface interacting mechanisms that mediate the interaction between $C$. albicans and bacteria have been characterized. These include localized production of glucans that are responsible for the adherence of $S$. mutans to C. albicans hyphal cells in the oral cavity (Kim and Koo, 2020). S. mutans binding affinity to glucan coated C. albicans hyphae exceed the binding forces between $C$. albicans and $S$. gordonii, allowing for the formation of larger biofilm structures during early phases of biofilm formation (Wan et al., 2021). This may provide a mechanism for glucans to favor S. mutans binding interactions with $C$. albicans in the oral cavity. In addition to glucans, extracellular DNA (eDNA) found in the biofilm matrix also plays a role in the S. mutansC. albicans interaction, especially during the initial attachment and early stages (Guo et al., 2021). The interaction between C. albicans and Helicobacter pylori was also further clarified, indicating strong attachment of the bacterial cells to the surface of C. albicans via multiple mechanisms (Palencia et al., 2022), including hydrophobic bonds between non-polar peptide chains or lipids on C. albicans cell walls and membranes of $H$. pylori. Hydrogen bonds may increase the strength of these interactions and formation of disulfide bonds between cysteine residues of surface proteins of both microorganisms may also be involved.

Naturally it is not only C. albicans genes and proteins that are responsible for the interaction between the yeast and various 
bacteria, as indicated by the involvement of $P$. gingivalis proteins highlighted above (Sztukowska et al., 2018; Bartnika et al., 2019). Karkowska-Kuleta and co-workers (2018) found that another of the extracellular virulence factors of $P$. gingivalis, a peptidylarginine deiminase enzyme, which converts protein arginine residues to citrullines, plays a role in the binding of $P$. gingivalis to C. albicans, possibly via citrullination of $C$. albicans surface proteins. In addition, during the initial interaction between $C$. albicans hyphae and S. gordonii, bacterial carbohydrate metabolism was seen to play a role as $f r u R, f r u B$, and fruA (encoding the transcriptional regulator, fructose-1phosphate kinase, and fructose-specific permease) were consistently upregulated in the presence of C. albicans and deletion of these genes caused formation of less robust biofilms (Jesionowski et al., 2016). The streptococcal glucocyltransferase (Gtf), which synthesize $\alpha$-glucan exopolymers, were also found to play a role in the interaction between $C$. albicans and S. oralis (Souza et al., 2020a). Interestingly, although deletion of $g f t R$ resulted in increased biofilm matrix, but not bacterial biomass, in monomicrobial biofilms, this deletion caused an increase in bacterial biomass in a PMB. The interaction between the commensal bacterium, Streptococcus intermedius, and $C$. albicans was found to cause increased biofilm formation (Mieher et al., 2021). Here pas (encoding a S. intermedius surface antigen, belonging to the Antigen I/II family of proteins) plays a role independent of Als3, as well as srtA (encoding sortase A - which allows for anchoring of surface proteins into the cell wall). Recently, Yang and co-workers (2018) also indicated the importance of the S. mutans adhesin, antigen I/II, for both the for the incorporation of $C$. albicans into the C. albicans-S. mutans biofilm and acid production by the biofilm. Interestingly, this interaction was also not dependent on the presence of Als1 and Als3. For all these studies, significant questions remain regarding the upstream signals and signaling pathways leading to the regulation of the various genes and mechanisms (Jakubovics, 2017).

\section{CONSEQUENCES OF THE COMPLEX INTERACTION}

\section{Impact on Pathogenesis}

The interaction between $C$. albicans and bacteria can influence the expression of specific virulence factors and may influence the outcome of co-infections (Allison et al., 2016; Dhamgaye et al., 2016) (Figure 2). Many of these co-infections are more pathogenic than single species infections. Examples include coinfection of C. elegans by C. albicans and Staphylococcus epidermidis (Holt et al., 2017) and co-infection of zebrafish by C. albicans and P. aeruginosa (Bergeron et al., 2017). This influence of $C$. albicans on pathogenesis in the oral cavity has received particular attention during the last six years. Sampaio and co-workers (2019) examined the ability of C. albicans to increase the cariogenicity of $S$. mutans (the bacterium involved in caries development) biofilms, using cultivation conditions that mimic the intake of sucrose during the day and lack of food during the night, over a period of $96 \mathrm{~h}$. They found that the PMB had greater volume and extracellular matrix (EXM) production and resulted in increased loss of dentine hardness.

Interestingly, the presence of C. albicans in caries-associated biofilms does not seem to always lead to increased cariogenicity. Willems and co-workers (2016) found that the interaction between $C$. albicans and $S$. mutans, may be less virulent. They grew PMBs for 24-72h on hydroxyapatite (HA) disks or glass slides and measured lactic acid concentrations, medium $\mathrm{pH}$ and the release of calcium from the HA disks. After $24 \mathrm{~h}$ the medium $\mathrm{pH}$ of all biofilms decreased to below $\mathrm{pH} 5.5$, at which the enamel

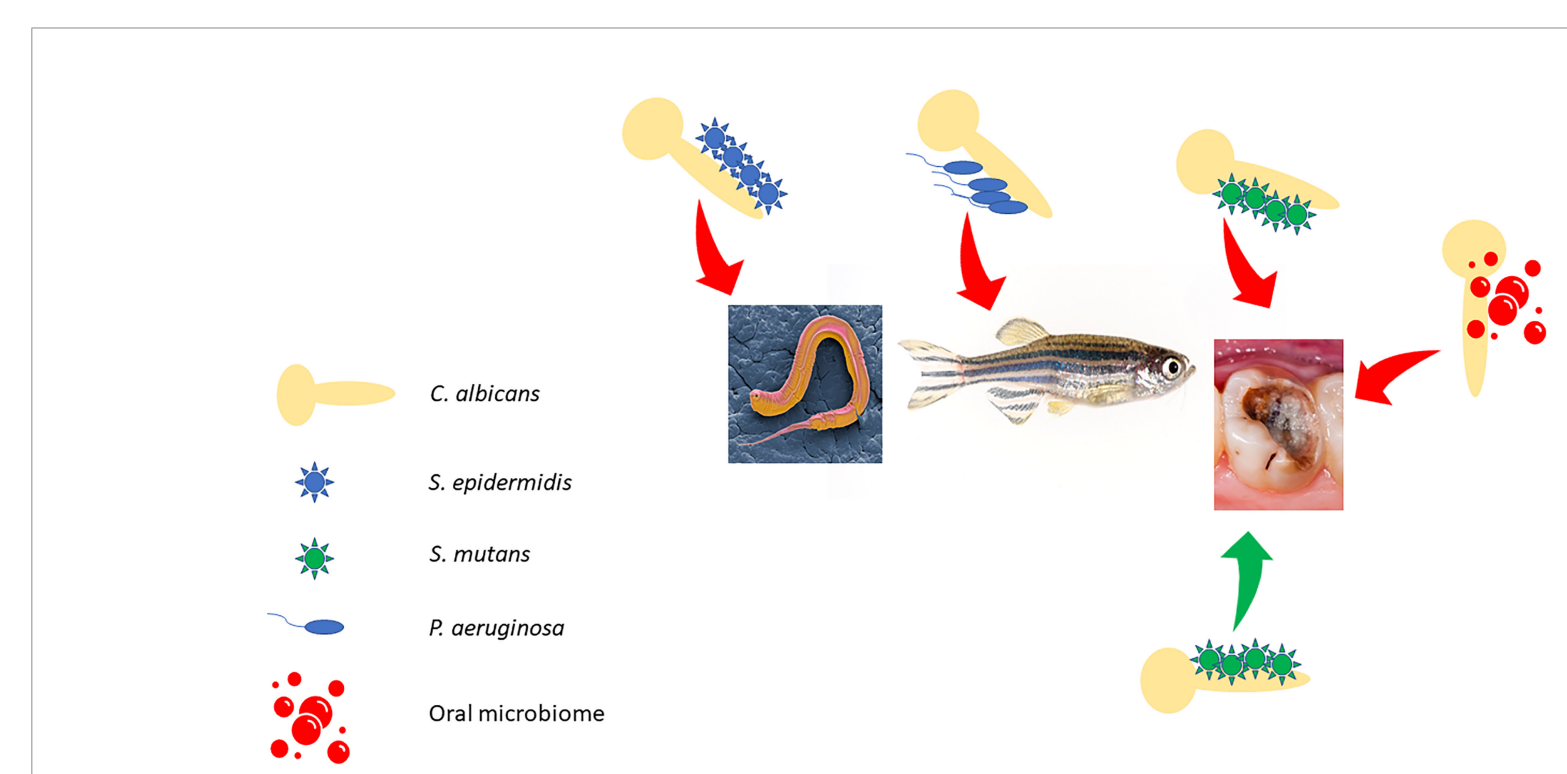

FIGURE 2 | Outcome of polymicrobial biofilm infections in different hosts/host niches. Red arrows indicate increased pathogenicity, and the green arrow indicates decreased pathogenicity as discussed in the text. 
would be solubilized. However, after 72h, C. albicans was able to increase the $\mathrm{pH}$ to above $\mathrm{pH} 5.5$, even though more lactic acid was produced by $S$. mutans, possibly by metabolizing the lactic acid and producing ammonia, which increases the $\mathrm{pH}$ (Janus et al., 2017). This increase in $\mathrm{pH}$ caused a decrease in calcium release. Similar results were obtained by Eidt and co-workers (2019) who grew biofilms on enamel slabs in the presence of glucose or sucrose for up to $72 \mathrm{~h}$. Thus, the interaction with $C$. albicans can reduce the acidogenic and cariogenic potential of $S$. mutans biofilms. This interaction may be partially mediated by the $C$. albicans quorum sensing molecule, farnesol. At low concentrations, farnesol can reduce acid as well as EXM production by S. mutans biofilms (Fernandes et al., 2018).

These studies provide useful information on potential interactions between $C$. albicans and single bacterial species, but the in vivo applicability may still be limited as the oral microbiome is a complex community consisting of many microbes interacting with each other (Janus et al., 2017). Morse and co-workers (2019) increased our understanding of the impact of an oral bacterial consortium on the expression of virulence factors (i.e. hyphal formation and expression of virulence related genes). They found that PMBs consisting of C. albicans and a consortium of S. sanguinis, S. gordonii, A. viscosus and Actinomyces odontolyticus resulted in a significant increase in hyphal production. This increase was abrogated if $P$. gingivalis was also included in the consortium. In addition, a significant increase in the expression of ALS3, EPA1, HWP1, PLD1, SAP4 and SAP6 was observed in the PMBs without $P$. gingivalis. The addition of $P$. gingivalis to the consortium resulted in a decrease in the expression of all these genes except SAP4. HWP1 and SAP6 are associated with the hyphal phenotype, while $P L D 1$ is also required for hyphal formation under certain circumstances (http://www.candidagenome.org/) and their downregulation may correlate with the decrease in hyphal formation in the presence of $P$. gingivalis.

The impact of $C$. albicans on the oral microbiome was recently studied. Jauns and co-workers (2017) investigated this using saliva derived biofilms under various oxygen levels (anaerobic, aerobic, aerobic with $5 \% \mathrm{CO}_{2}$ ). In anaerobic biofilms, no growth of $C$. albicans was observed, but in biofilms grown in the presence of oxygen, C. albicans did grow as part of the biofilm, forming extensive hyphae in the presence of $\mathrm{CO}_{2}$. Unexpectedly, C. albicans did not influence lactic acid production or protease activity in any of the biofilms. However, since hyphae can act as sites of interaction between C. albicans and bacteria, the authors investigated the influence of C. albicans on the microbiome of early biofilms in the presence of $\mathrm{CO}_{2}$. They found that more anaerobic bacteria (such as Veillonella spp., Leptotrichia spp., Prevotella spp. and Fusobacterium spp.) are present in C. albicans containing PMBs. These bacteria have been associated with various oral and dental infections. Similarly, Du and co-workers (2021) found that the introduction of $C$. albicans into biofilms obtained from saliva, resulted in significant changes in the microbial ecology, including increased growth of Streptococcus spp. and Gemella sanguinis as well as decreased growth of Klebsiella pneumoniae, Haemophilus parainfluenza and Rothia dentocariosa. However, in this study, the addition of
C. albicans significantly increased acidogenicity and cariogenicity of these biofilms by upregulating bacterial genes associated with acid production. This increase in cariogenicity by C. albicans was also seen in a rat caries model. This interaction was dependent on C. albicans PHR2, which encodes a $\mathrm{pH}$ responsive glycosidase, indicating the importance of carbohydrate metabolism in this interaction.

These studies have shed light on the very complex interactions between $C$. albicans and bacteria and indicate that the species composition of a PMB can have a significant influence on the behavior of the biofilm members (including virulence). This would presumably hold true not only for oral biofilms, but for other biofilms both in the environment and the host.

\section{Impact on the Host Immune Response}

The outcome of a PMB infection is not only dependent on the species composition of the biofilm, but also on the interaction between the biofilm and the host, especially the host's immune system.

Cytokines are small proteins or glycoproteins that can influence both the innate and adaptive immune response. They are mainly produced by helper T-cells and macrophages, although cytokine production can be induced in almost all other cells. Many researchers have examined the influence of $\mathrm{PMB}$ infection on the production of cytokines by various cell types. The effect of mono-and polymicrobial biofilms of $C$. albicans, S. mutans, S. gordonii and Aggregatibacter actinomycetemcomitans on production of the cytokines, interleukin-8 (IL-8) and tumor necrosis factor- $\alpha$ (TNF- $\alpha$ ), by whole blood was determined (Bhardwasj et al., 2020). They observed that both cytokines were most induced when blood was stimulated with the PMB as well as its supernatant, compared to any of the monomicrobial biofilms. However, supernatants of $C$. albicans- $P$. gingivalis biofilm reduced the production of IL- 8 by monocyte-like cells although it did increase production of interleukin $1 \beta$ (Bartnicka et al., 2020). The response by TNF- $\alpha$ was dependent on the incubation time since after an initial increase, the levels of this cytokine decreased. These authors found that the presence of $C$. albicans can stimulate $P$. gingivalis to produce gingipains, which can have proteolytic activity against cytokines, thus weakening the immune response. This protection from the host was confirmed in a mouse model of polymicrobial infection.

It is known that oral candidiasis may predispose a host to secondary systemic infection by S. aureus (Allison et al., 2019; Van Dyck et al., 2021). In this case adhesion of $S$. aureus to $C$. albicans as well the host immune response are needed for bacterial dissemination. It was found that macrophages cocultured with C. albicans were highly attracted toward hyphae and preferentially engulfed $S$. aureus attached to the hyphae. This increase in phagocytosis provides more opportunity for dissemination of $S$. aureus to lymph nodes. Interestingly, although adhesion between C. albicans and S. aureus was not influenced by candidalysin [C. albicans secreted protein involved in immune response activation and immune cell recruitment (Naglik et al., 2019)], this protein was required for dissemination of S. aureus (Van Dyck et al., 2021). In addition, the interaction between PMBs on titanium and mucosal tissue was evaluated 
using a non-commercial in vitro organotypic mucosal model (Souza et al., 2020b). They found that C. albicans-Streptococcus spp. biofilms formed on titanium, caused increased tissue damage without increased proinflammatory cytokine production, compared to $C$. albicans monomicrobial biofilms.

These studies indicate the complex tri-partite interaction between $C$. albicans, bacteria and the host immune response that is still largely underexplored, although it will have significant impact on the outcome of co-infections and disease.

\section{Impact on Antimicrobial Resistance}

It is well known that the close relationships between microbes may increase the resistance of one or more of the microbial partners to antimicrobials (Maisetta and Batoni, 2020). Several recent studies have increased our understanding regarding the influence of $C$. albicans-bacterial interaction on antimicrobial resistance of the microbes.

The C. albicans-S. aureus interaction has received significant attention in this regard, with various authors showing that the presence of $C$. albicans in the PMB significantly enhanced tolerance of $S$. aureus to vancomycin and that this is mediated by C. albicanssecreted molecules (Kong et al., 2016; Kong et al., 2017; Srinivasan et al., 2017; Vila et al., 2021). It was seen that $\beta$-1,3-glucan, a fungal cell wall component that is also found in the EXM, coats the bacterial cells, thus protecting them from the antibiotic (Kong et al., 2016). C. albicans also increased the tolerance of $P$. aeruginosa to the first line antibiotic, meropenem (Alam et al., 2020) as well as the tolerance of S. gordonii to clindamycin (Montelongo-Jauregui et al., 2019), possibly also due to the presence of C. albicans-secreted mannan and glucan. Another molecule secreted by C. albicans is the quorum sensing molecule, farnesol. Kong and colleagues (2017) found that this molecule increased oxidative stress in $S$. aureus, leading to upregulation of drug efflux pumps and subsequent increased vancomycin efflux.

Using a mouse subcutaneous catheter model of C. albicans-S. aureus biofilm infection, Vila and colleagues (2021) indicated that the observed in vitro vancomycin resistance was also observed in vivo. Further investigation revealed that $C$. albicans causes modulation of $S$. aureus biofilm related genes (including those that encode repressors of autolysis, $\operatorname{lrg} \mathrm{A}$ and $\operatorname{lrgB}$ ), which would lead to cell lysis and eDNA production. It was established that $C$. albicans-S. aureus biofilms do contain higher levels of eDNA and that DNAse treatment of these biofilms sensitized $S$. aureus to vancomycin and allowed the diffusion of vancomycin through the EXM. Therefore, it was proposed that in a mixed biofilm, the secreted/released matrix components and other molecules may protect $S$. aureus from this antibiotic. Interestingly, eDNA was also found to be involved in the increased miconazole resistance of C. albicans in C. albicans-S. aureus biofilms (Kean et al., 2017), indicating that the protective effect of PMBs are also applicable to $C$. albicans. This was further demonstrated by Kim and colleagues (2018), who saw that the $S$. aureus extracellular polysaccharide $\alpha$ glucan, can directly bind to $C$. albicans cells and sequestered fluconazole, reducing uptake of the antifungal.

The clinical relevance of these studies was indicated by $\mathrm{Hu}$ and colleagues (2021) who observed that, in both local and systemic infection murine models, polymicrobial infection with
C. albicans and $S$. aureus increased pathogenesis. In addition, $S$. aureus $\beta$-lactam and vancomycin resistance genes and $C$. albicans azole resistance genes were significantly upregulated in these infections, resulting in both antibiotic and antifungal drug resistant infections. It may also be speculated that the effect of these secreted compounds indicates that physical contact between $C$. albicans and bacteria is not a requirement for the observed increase in antimicrobial resistance.

In contrast, C. albicans matrix components and farnesol were found not to be involved in the increased resistance of $S$. aureus to other antibiotics (oxacillin, ciprofloxacin, delafloxacin, and rifampicin) (Nabb et al., 2019). Rather, PMBs were found to decrease the available glucose at a faster rate than monomicrobial biofilms. This enhanced metabolism was also observed by $\mathrm{He}$ and co-workers (2017) using RNASeq and biochemical analyses. According to $\mathrm{Nabb}$ and co-workers (2019), the competition for glucose results in decreased metabolism of $S$. aureus, with more cells containing less ATP and with lower membrane potential in polymicrobial cultures compared with monomicrobial cultures. These persister populations may explain the increased antibiotic tolerance. It will be important to see if this mechanism is also relevant in vivo, where glucose levels are often limited and greater competition for glucose, or co-utilization of alternative carbon sources, could be expected. The role of both bacterial persister cell in antibiotic resistance in the context of monomicrobial biofilms have been studied, however the role of C. albicans persister cells seem to be more controversial with different findings regarding the occurrence of persister cells in C. albicans biofilms (Denega et al., 2019; Galdiero et al., 2020b). However, the role of bacterial (or C. albicans) persister cells in polymicrobial biofilms, especially their influence on drug tolerance, has not been studied yet. Other C. albicans-bacteria interactions that influenced antimicrobial resistance, but for which the mechanism(s) have not yet been studied are indicated in Table 2.

Although the focus of most research regarding the consequence of $\mathrm{PMB}$ formation on resistance, has been directed towards antimicrobial resistance, this can be seen as a type of stress resistance and several recent papers have included other types of stress resistance, such as starvation resistance (Gao et al., 2016), resistance to non-antimicrobial drugs, such as nordihydroguaiaretic acid (Fourie et al., 2017), resistance to oxidative stress (Lobo et al., 2019) and serum (Guo et al., 2020). These studies all indicate that not only are PMBs generally more resistant to antimicrobials, but also to a variety of other stresses. Further mechanistic insights into this phenomenon may identify novel drugs or drug targets.

\section{IN SEARCH OF NOVEL THERAPEUTIC SOLUTIONS TO POLYMICROBIAL BIOFILMS}

During the last five years numerous researchers have attempted to find novel treatment or prevention options for PMBs. Many of these studies have investigated plants or their extracts (Table 3). 
TABLE 2 | Candida albicans-bacteria interactions that influence antimicrobial resistance.

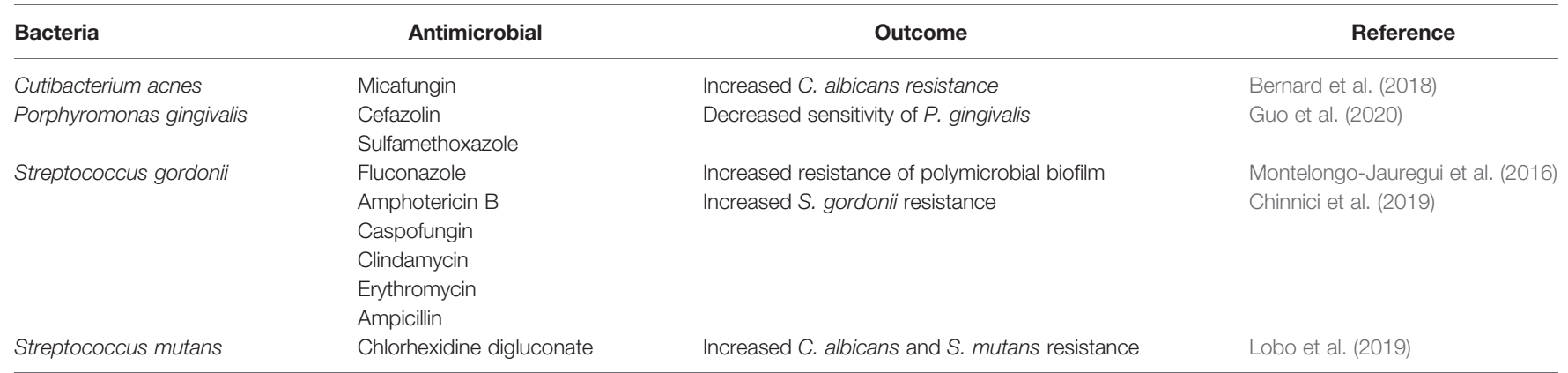

Although the data from plant extracts seldom lead to treatment options in Western medicine, plants do contain several active compounds that, when purified, can inhibit growth of various microbes and may be assessed for their specific ability to inhibit PMBs (Table 4). Unfortunately, most of the research so far lack detail investigation of the mechanisms of action, or of toxicity studies in mammalian systems. Thus, making the translation of the in vitro results to application very limited.

Since biofilm formation is coordinated by quorum sensing systems, several researchers have targeted this system in the development of novel treatment options. The C. albicans quorum sensing molecule, farnesol, was found to reduce hyphal formation by $C$. albicans in a biofilm with $S$. mutans did not have any effect on the growth of the bacteria (Černáková et al., 2018; Rocha et al., 2018). Feldman and co-workers (2016) studied the antibiofilm activity of thiazolidinedione- 8 and found that it was able to reduce biomass of C. albicans-S. mutans biofilms by affecting various processes, including $\mathrm{S}$. mutans quorum sensing, EPS production and oxidative stress. The chemical could also affect $C$. albicans hyphal formation. This compound was successfully incorporated into a sustained-release membrane for possible application in clinical settings (Feldman et al., 2017). Phenazine-1-carboxamide, is a bacterial phenazine

TABLE 3 | Plants and extracts with activity against Candida albicans containing polymicrobial biofilms.

\begin{tabular}{|c|c|c|c|c|}
\hline Plant/extract & $\begin{array}{l}\text { Antimicrobial used in } \\
\text { combination }\end{array}$ & $\begin{array}{l}\text { Bacterium interacting with } \\
\text { C. albicans }\end{array}$ & $\begin{array}{l}\text { Effect on polymicrobial } \\
\text { biofilm }\end{array}$ & Reference \\
\hline Commercial clove (Syzygium aromaticum) essential oil & $\begin{array}{l}\text { Fluconazole } \\
\text { Mupirocin }\end{array}$ & S. aureus & $\begin{array}{l}10 x \text { increase in anti-biofilm } \\
\text { activity } \\
4 x \text { increase in anti-biofilm } \\
\text { activity }\end{array}$ & $\begin{array}{l}\text { Budzyńska } \\
\text { et al. (2017) }\end{array}$ \\
\hline Commercial rosemary (Rosmarinnus officialis) extract & & $\begin{array}{l}\text { E. faecalis/ } \\
\text { P. aeruginosa/ } \\
\text { S. aureus/ } \\
\text { S. mutans }\end{array}$ & Anti-biofilm activity & $\begin{array}{l}\text { De Oliveira et al. } \\
\text { (2017a) }\end{array}$ \\
\hline Commercial thyme (Thymus vulgaris) extract & & $\begin{array}{l}\text { E. faecalis/ } \\
\text { P. aeruginosal } \\
\text { S. aureus/ } \\
\text { S. mutans }\end{array}$ & Anti-biofilm activity & $\begin{array}{l}\text { De Oliveira et al. } \\
\text { (2017b) }\end{array}$ \\
\hline Cranberry extract & & S. mutans & $\begin{array}{l}\text { Inhibited cariogenic virulence } \\
\text { properties }\end{array}$ & $\begin{array}{l}\text { Philip et al. } \\
\text { (2019) }\end{array}$ \\
\hline $\begin{array}{l}\text { Cajuputs candy (active ingredient is Melaleuca cajuputi } \\
\text { essential oil) }\end{array}$ & & S. mutans & $\begin{array}{l}\text { Inhibited early biofilm } \\
\text { development } \\
\downarrow \text { hyphal formation and } \\
\text { bacterial adhesion }\end{array}$ & $\begin{array}{l}\text { Wijaya et al. } \\
(2019)\end{array}$ \\
\hline Ethanol extract of Lerak (Sapindus rarak) seeds & & $\begin{array}{l}\text { Combination of } E \text {. coli, } P \text {. } \\
\text { aeruginosa and } S \text {. aureus }\end{array}$ & $\begin{array}{l}\text { Inhibits pre-formed biofilms } \\
\text { and removes EXM }\end{array}$ & $\begin{array}{l}\text { Pratiwi \& } \\
\text { Hamzah (2020) }\end{array}$ \\
\hline $\begin{array}{l}\text { Commercial lemongrass (Cymbopogon flexuosus) } \\
\text { essential oil }\end{array}$ & & S. aureus & $\begin{array}{l}\text { Dose dependent anti-biofilm } \\
\text { activity } \\
\text { Inhibition of EXM production }\end{array}$ & $\begin{array}{l}\text { Gao et al. } \\
(2020)\end{array}$ \\
\hline Methanol extract of Allium oschaninii & & Klebsiella pneumoniae & Inhibited biofilm formation & $\begin{array}{l}\text { Galdiero et al. } \\
\text { (2020a) }\end{array}$ \\
\hline Methanol extract of Allium ursinum & & K. pneumoniae & Inhibited biofilm formation & $\begin{array}{l}\text { Galdiero et al. } \\
\text { (2020a) }\end{array}$ \\
\hline Ethanol extract of Rhamnus prinoides & & S. mutans & Inhibited biofilm formation & $\begin{array}{l}\text { Campbell et al. } \\
(2020)\end{array}$ \\
\hline $\begin{array}{l}\text { LongZhang gargle (root and stem extract of Toddalia } \\
\text { asiatica and Cimicifuga foetida }\end{array}$ & & S. mutans & $\begin{array}{l}\text { Inhibited biofilm formation } \\
\downarrow \text { hyphal formation, impacting } \\
\text { biofilm structure }\end{array}$ & $\begin{array}{l}\text { Gong et al. } \\
(2021)\end{array}$ \\
\hline
\end{tabular}


TABLE 4 | Plant-derived compounds with activity against polymicrobial biofilms.

\begin{tabular}{|c|c|c|c|c|}
\hline Compound & Plant source & $\begin{array}{l}\text { Bacterium interacting with } \\
\text { C. albicans }\end{array}$ & Effect on polymicrobial biofilm & Reference \\
\hline Curcumin & Curcuma longa & $\begin{array}{l}\text { S. mutans } \\
\text { S. aureus-P. aeruginosa- E. coli }\end{array}$ & $\begin{array}{l}\text { Inhibition } \\
\text { Downregulation of C. albicans agglutinin-like genes } \\
\text { Inhibition }\end{array}$ & $\begin{array}{l}\text { Li et al. (2019) } \\
\text { Tan et al. (2019) } \\
\text { Ma et al. (2020) } \\
\text { Hamzah et al. (2020a) }\end{array}$ \\
\hline $\begin{array}{l}\text { Gymnemic } \\
\text { acid }\end{array}$ & $\begin{array}{l}\text { Gymnema } \\
\text { sylvestre }\end{array}$ & S. gordonii & $\begin{array}{l}\text { Inhibit eDNA production, hyphal formation, adhesion. Downregulation } \\
\text { of S. gordonii gtfG1) }\end{array}$ & $\begin{array}{l}\text { Veerapandian and } \\
\text { Vediyappan (2019) }\end{array}$ \\
\hline Luteolin & Various & E. faecalis & $\begin{array}{l}\text { Inhibition } \\
\text { Decrease in EXM production }\end{array}$ & Fu et al. (2021) \\
\hline Nepodin & Rumex crispus & $\begin{array}{l}\text { S. aureus } \\
\text { A. baumannii }\end{array}$ & $\begin{array}{l}\text { Inhibition } \\
\text { Decrease hyphal formation }\end{array}$ & Lee et al. (2019) \\
\hline Quercetin & Various & S. aureus- $P$. aeruginosa- E. coli & Anti-biofilm activity & Hamzah et al. (2020b) \\
\hline Zerumbone & $\begin{array}{l}\text { Zingiber } \\
\text { zerumbet }\end{array}$ & $\begin{array}{l}\text { S. aureus } \\
\text { S. aureus-P. aeruginosa- E. coli }\end{array}$ & Anti-biofilm activity & $\begin{array}{l}\text { Shin and Esom (2019) } \\
\text { Hamzah et al. (2020c) }\end{array}$ \\
\hline
\end{tabular}

derivative - whose production is regulated by quorum sensing systems. This compound is well known for its antifungal activity (Peng et al., 2018) and was evaluated for its ability to inhibit $C$. albicans-S. aureus biofilms (Kanugala et al., 2019). It was found to completely inhibit biofilm formation when incorporated into porous silica nanoparticles and could successfully be used as antibiofilm coating on urinary catheters in vitro.

Other small molecules have also been studied for their effects on PMBs. Fluoride is known for its actions against cariogenic bacteria. Yassin and co-workers (2016) used this to develop fluoride releasing dental polymer that was able to inhibit the growth of C. albicans-Lactobacillus casei-S. mutans PMBs. Sodium trimetaphosphate is a supplement to fluoride in oral health and has beneficial effects on tooth enamel, but its effect on oral biofilms are not well studied (Cavazana et al., 2019), although it could reduce the metabolic activity and production of EXM by C. albicans-S. mutans biofilms. When combined with fluoride, it was also able to reduce biofilm biomass significantly. Another strategy was to test molecules with anti-C. albicans activity for their ability to inhibit PMBs. One such compound, 5hydroxymethyl-2-furaldehyde, was found to inhibit C. albicans$S$. epidermidis biofilm formation, by affecting attachment and virulence factors of $C$. albicans (i.e. hyphal formation, secretion of hydrolytic enzymes) as well as EXM, in vitro (Swetha et al., 2021). This compound also had a protective effect against infection in the C. elegans model. Another compound that has recently shown antibacterial and antifungal activity is auranofin - a trialkylphosphine gold complex. This compound was also recently shown to be able to inhibit $C$. albicans-S. aureus biofilms (She et al., 2020). Bay 11-7085 is another small molecule with possible antibacterial activity that could prevent formation of $C$. albicans-S. aureus biofilms, by inhibiting initial attachment and biofilm growth, especially of C. albicans (Escobar et al., 2021).

Various macromolecules, such as guanylated polymethacrylates, and branched polyethyleneimine based amphiphilic cationic macromolecules, were recently found to have activity against $C$. albicans-S. aureus biofilms (Qu et al., 2016; Mukherjee et al., 2020), but the most studied polymer was chitosan, with various authors indicating the ability of different forms/derivatives of molecule to inhibit PMBs (Tan et al., 2016; Ikono et al., 2019). This has led to the development of chitosan-coated surgical sutures and catheters that are able to prevent C. albicans-S. epidermidis biofilm formation (Prabha et al., 2021; Rubini et al., 2021). Chitosan has also been developed as a nanocarrier material for other potential antibiofilm compounds. Vieira and co-workers, (2019) used chitosan to coat iron oxide nanoparticles to form a carrier system for chlorhexidine. These nanoparticles showed similar or better results against $C$. albicans-S. mutans biofilms than free chlorhexidine. Chitosan nanoparticles loaded with curcumin was also effective against $C$. albicans-S. aureus biofilms (Ma et al., 2020). Similar nanoparticles were also loaded with cellobiose dehydrogenase and deoxyribonuclease I. These nanoparticles could penetrate the EXM to act against $C$. albicans-S. aureus biofilms and degrade eDNA in the matrix (Tan et al., 2020).

In recent years, the effectiveness of metal nanoparticles against $C$. albicans $\mathrm{PMB}$ have also been studied. Silver nanoparticles were found to be effective against $C$. albicans-E. coli (Yasinta et al., 2021) and C. albicans-S. aureus biofilms and could be incorporated into silicone, that may be used for the manufacture of catheters (Lara and Lopez-Ribot, 2020) or maxillofacial prosthesis (Chong et al., 2021). Selenium nanoparticles (stabilized with either chitosan or bovine serum albumin) were tested for their ability to inhibit C. albicans-S. aureus biofilms (Filipovic et al., 2021). The authors found that selenium nanoparticles stabilized with bovine serum albumin had reduced cytotoxicity towards mammalian cells, but significantly inhibited the dual species biofilms in a dose dependent manner. It was observed that $C$. albicans was more sensitive to these nanoparticles than $S$. aureus in the dual species biofilms.

Certain metal cross linked monomers have antibacterial activity and this was exploited to develop a dental pit and fissure selfadhesive sealant, containing di-n-butyl-dimethacrylate-tin, which exhibited good activity against C. albicans-S. mutans biofilms, without an effect on the mechanical properties of the sealant or causing cytotoxicity against mouse fibroblasts (Cocco et al., 2021).

Researchers have also focused on combination therapy in efforts to inhibit PMBs (Table 5). Although optimization of concentrations is often an issue in these studies (Rodrigues et al., 2017), this approach holds promise and clearly indicates the requirement for the addition of antifungal drugs when dealing with these types of biofilms. The importance of antifungals in the 
treatment of PMBs was also demonstrated by Luo and coworkers (2021), who found that C. albicans-S. aureus biofilms treated with amphotericin $\mathrm{B}$, exhibited not only a reduction in $C$. albicans cell numbers, but also a decrease in bacterial cells - due to the supportive role of $C$. albicans hyphae in the development of these biofilms.

An alternative treatment option that has gained a lot of interest recently, is the use of antimicrobial peptides and peptoids. The amphiphilic nature of antimicrobial peptides allows them to bind to microbial membranes, causing disruption. A previously identified antifungal peptide product of the immunoglobulin gene, IGHJ2, was studied for its ability to inhibit formation of $C$. albicans- $P$ aeruginosa-S. aureus $\mathrm{PMBs}$ (Di Fermo et al., 2021). This natural peptide was, however, not very effective in inhibiting biofilm formation in vitro. In a wound infection model, the peptide did cause a reduction in $S$. aureus and $C$. albicans numbers, but these were not statistically significant. The antimicrobial activity of natural peptides can be enhanced by various modifications to form synthetic peptides. Three such synthetic peptides have recently been demonstrated to be effective against C. albicans-S. aureus and C. albicans-K. pneumoniae biofilms in vitro and in mice and G. mellonella infections (Gupta et al., 2019; Galdiero et al., 2021a; Maione et al., 2021). Peptoids are peptide-mimics with increased resistance to proteases and therefore better stability in vivo (Luo et al., 2017). Three peptoids were tested against $C$. albicans-S. aureus and C. albicans-E. coli biofilms. Although these peptoids were able to reduce the cell numbers of $C$. albicans and bacteria, differences between the peptoids were observed depending on the composition of the dual species biofilms.

Other amphiphilic molecules that have been studied for their ability to prevent PMB formation, are biosurfactants, including lipopeptides, rhamnolipids and sophorolipids (Ceresa et al., 2021). Of the biosurfactants tested, one containing rhamnolipids was found to be most effective in preventing $C$. albicans-S. aureus and C. albicans-S. epidermidis biofilm formation. The antimicrobial properties of other lipids, including fatty acids, are well known and their effect on PMBs have also been evaluated. Saw palmetto oil, and the main fatty acids myristic acid (14:0) and lauric acid (12:0), were found to significantly inhibit C. albicans-S. aureus, C. albicans-E. coli biofilms as well as PMBs consisting of all three microbes in vitro and in C. elegans (Kim et al., 2021). Similar results were obtained for pentadecanoic acid (15:0) and pentadecanal against C. albicans-K. pneumoniae biofilms (Galdiero et al., 2021b). These lipids and lipid-based compounds may hold promise as a coating for medical implants (Ceresa et al., 2021; Galdiero et al., 2021b).

Although bacteriophages are an innovative strategy to combat polymicrobial bacterial biofilms (Mgomi et al., 2021), this is still unexplored in the context of C. albicans polymicrobial biofilms. Szafránski and co-workers (2017) did hypothesize how the interactions within the complex multispecies oral biofilm, containing C. albicans and various bacteria, may be targeted by bacteriophages directed at the different bacterial members. Interestingly, the $P$. aeruginosa phage, $\mathrm{Pf} 4$, was able to directly inhibit $C$. albicans biofilm formation as well as preformed biofilms. possibly by sequestrating iron (Nazik et al., 2017). These studies open the doors to further explore the applicability of bacteriophages in the inhibition of C. albicansbacterial PMBs.PMBs can also form on non-implanted surfaces where disinfectants may be used to remove them. One such surface is dental unit waterlines. Costa and co-workers (2016) examine the ability of three recommended disinfectants to prevent or remove PMBs, consisting of C. albicans,

TABLE 5 | Combination therapy against polymicrobial biofilms.

\begin{tabular}{|c|c|c|c|}
\hline Drug combinations & $\begin{array}{l}\text { Bacteria interacting } \\
\text { with C. albicans }\end{array}$ & Effect on polymicrobial biofilm & Reference \\
\hline Polymyxin and amphotericin B & $P$. aeruginosa & $\begin{array}{l}\text { Combination of amphotericin B and highest concentration of } \\
\text { polymyxin could eradicate polymicrobial biofilms }\end{array}$ & $\begin{array}{l}\text { Rodrigues } \\
\text { et al. (2017) }\end{array}$ \\
\hline Flucloxacillin, ciprofloxacin and fluconazole & $\begin{array}{l}\text { S. aureus and } P \text {. } \\
\text { aeruginosa }\end{array}$ & $\begin{array}{l}\text { Combination of all three drugs was required to inhibit all three } \\
\text { microbes in the biofilm }\end{array}$ & $\begin{array}{l}\text { Townsend } \\
\text { et al. (2017) }\end{array}$ \\
\hline Anidulafungin and tigecycline & S. aureus & Synergism against in vivo intra-abdominal biofilms & $\begin{array}{l}\text { Rogiers et al. } \\
(2018)\end{array}$ \\
\hline 2-aminobenzimidazole and curcumin & S. aureus & Increased biofilm inhibition by combination & $\begin{array}{l}\text { Tan et al. } \\
\text { (2019) }\end{array}$ \\
\hline Caspofungin and polymyxin B & P. aeruginosa & $\begin{array}{l}\text { Combination was able to significantly reduce the total biomass of } \\
\text { mixed biofilms }\end{array}$ & $\begin{array}{l}\text { Fernandes } \\
\text { et al. (2020) }\end{array}$ \\
\hline $\begin{array}{l}\text { Antifungal chalcone-based derivative and antibacterial } \\
\text { polycyclic anthracene-maleimide adduct }\end{array}$ & S. aureus & Synergistic biofilm inhibition & $\begin{array}{l}\text { Bonvicini } \\
\text { et al. (2021) }\end{array}$ \\
\hline Berberine and amphotericin B & S. aureus & $\begin{array}{l}\text { Synergistic biofilm inhibition with reduced hyphal formation and } \\
\text { adhesion }\end{array}$ & $\begin{array}{l}\text { Gao et al. } \\
(2021)\end{array}$ \\
\hline $\begin{array}{l}\text { Farnesol combined with myricetin, } \mathrm{C} 135^{\star} \text { and compound } \\
1771^{\star \star}\end{array}$ & S. mutans & Eliminated bacteria from dual species biofilm & $\begin{array}{l}\text { Lobo et al. } \\
\text { (2021) }\end{array}$ \\
\hline C135 and fluoride & S. mutans & Eliminated bacteria from dual species biofilm & $\begin{array}{l}\text { Lobo et al. } \\
\text { (2021) }\end{array}$ \\
\hline Bacterial biosurfactant and DNase & S. epidermidis & Synergistic activity against biofilms & $\begin{array}{l}\text { Srikanth et al. } \\
\text { (2021) }\end{array}$ \\
\hline
\end{tabular}

*4-OH chalcone.

**5-phenyl-1,3,4-oxadiazol-2-yl)carbamoyl]methyl 2-\{naphtho[2,1-b]furan-1-yl\}acetate). 
P.aeruginosa and the amoeba, Vermamoeba vermiformis. The efficiency of the three disinfectants depended on their composition, and the concentration used, although none were able to completely eradicate mature PMBs. Of the three species in the biofilms, C. albicans was the most sensitive and $V$. vermiformis the least. Novel antiseptics, such as pyridoxinebased quaternary ammonium derivatives of terbinafine, are also investigated for their ability to eradicate C. albicans-S. aureus biofilms and was found to be very effective against both organisms (Garipov et al., 2020). The mechanisms of action include membrane damage and targeting of pyridoxaldependent enzymes.

PMBs can also be inhibited without the use of chemicals. An example of such an approach is the use of atmospheric-pressure cold plasma, generated by gas ionization leading to the production of reactive oxygen and nitrogen species UV radiation and an electromagnetic field. This approach was able to inhibit both microbes in C. albicans-S. aureus biofilms in vitro and in reconstituted oral epithelium, without evidence of cytotoxicity (Aparecida Delben et al., 2016). Another nonchemical approach is the use of antimicrobial blue light (Ferrer-Espada et al., 2018). This antimicrobial action is thought to be mediated by intracellular porphyrins that act as photosensitizers. Exposure of a C. albicans-P. aeruginosa biofilm, grown in 96-well plates, to blue light at radiant exposure of either 216 or $500 \mathrm{~J} / \mathrm{cm}^{2}$, caused a decrease in cell numbers for $C$. albicans, but an increased for $P$. aeruginosa, compared to their monomicrobial counterparts. Similar experiments performed using CDC biofilm reactor, showed a decrease in cells for both C. albicans and P. aeruginosa (Ferrer-Espada et al., 2019). It should however be noted that $500 \mathrm{~J} / \mathrm{cm}^{2}$ caused significant reduction in metabolic activity of keratinocytes. Similar results were obtained by Tsutsumi-Arai and co-workers (2021), who indicated that both C. albicans and S. mutans cell numbers in a dual species biofilm are reduced by exposure to blue light, with $C$. albicans being more sensitive. The treatment caused an increase in reactive oxygen species, and this could be correlated to the higher levels of porphyrins present in C. albicans cells.

\section{REFERENCES}

Abusrewil, S., Brown, J. L., Delaney, C. D., Butcher, M. C., Kean, R., Gamal, D., et al. (2020). Filling the Void: An Optimized Polymicrobial Interkingdom Biofilm Model for Assessing Novel Antimicrobial Agents in Endodontic Infection. Microorganisms 8, 1988. doi: 10.3390/microorganisms 8121988

Alam, F., Catlow, D., Di Maio, A., Blair, J. M. A., and Hall, R. A. (2020). Candida albicans Enhances Meropenem Tolerance of Pseudomonas aeruginosa in a Dual-Species Biofilm. J. Antimicrob. Chemother. 75, 925-935. doi: 10.1093/jac/ dkz514

Allison, D. L., Scheres, N., Willems, H. M. E., Bode, C. S., Krom, B. P., and Shirtliff, M. E. (2019). The Host Immune System Facilitates Disseminated Staphylococcus aureus Disease Due to Phagocytic Attraction to Candida albicans During Coinfection: A Case of Bait and Switch. Infect. Immun. 87, e00137-19. doi: 10.1128/IAI.00137-19

Allison, D. L., Willems, H. M. E., Jayatilake, J. A. M. S., Bruno, V. M., Peters, B. M., and Shirtliff, M. E. (2016). Candida-Bacteria Interactions: Their Impact on Human Disease. Microbiol. Spectr. 4. doi: 10.1128/microbiolspec.VMBF-0030-2016
It is evident that significant research efforts are focused on finding novel therapeutic options for C. albicans containing biofilms, many of these studies included possible mechanisms of actions as well as cytotoxicity assays and in vivo testing. It is hoped that these practices will become more widespread and will increase the likelihood of finding options that have the potential to be translated from the laboratory (or field) to the clinical setting.

\section{DISCUSSION: FUTURE PROSPECTS}

We are entering an exciting time in the study of pathogenic microbes, where the intersection between traditional medical microbiology and microbial ecology is becoming more evident. This is to be expected since PMBs and polymicrobial infections form unique habitats where not only the microbes interact with each other, but also with the host, resulting in complex and often as yet unpredictable outcomes for disease progression and antimicrobial efficacy. It is envisioned that tools, such as metagenomic and metatranscriptomic analyses, more common place in microbial ecology may add significant new knowledge regarding not only the organisms present in polymicrobial biofilms in the host, but also the molecular interaction between them. This is indeed a complex field, but as indicated in this review, many exciting advances are being made.

\section{AUTHOR CONTRIBUTIONS}

The author confirms being the sole contributor of this work and has approved it for publication.

\section{FUNDING}

Funding was provided by the National Research Foundation (NRF) of South Africa to CP (grant number 115566).

Aparecida Delben, J., Evelin Zago, C., Tyhovych, N., Duarte, S., and Eduardo Vergani, C. (2016). Effect of Atmospheric-Pressure Cold Plasma on Pathogenic Oral Biofilms and In Vitro Reconstituted Oral Epithelium. PloS One 11, e0155427. doi: 10.1371/journal.pone.015542

Arzmi, M. H., Alnuaimi, A. D., Dashper, S., Cirillo, N., Reynolds, E. C., and McCullough, M. (2016). Polymicrobial Biofilm Formation by Candida albicans, Actinomyces naeslundii, and Streptococcus mutans Is Candida albicans Strain and Medium Dependent. Med. Mycol. 54, 856-864. doi: 10.1093/mmy/myw042

Ascione, C., Sala, A., Mazaheri-Tehrani, E., Paulone, S., Palmieri, B., Blasi, E., et al. (2017). Herpes Simplex Virus-1 Entrapped in Candida albicans Biofilm Displays Decreased Sensitivity to Antivirals and UVA1 Laser Treatment. Ann. Clin. Microbiol. Antimicrob. 16, 72. doi: 10.1186/s12941-017-0246-5

Bartnicka, D., Gonzalez-Gonzalez, M., Sykut, J., Koziel, J., Ciaston, I., Adamowicz, K., et al. (2020). Candida albicans Shields the Periodontal Killer Porphyromonas gingivalis From Recognition by the Host Immune System and Supports the Bacterial Infection of Gingival Tissue. Int. J. Mol. Sci. 21, 1984. doi: 10.3390/ijms21061984 
Bartnicka, D., Karkowska-Kuleta, J., Zawrotniak, M., Satała, D., Michalik, K., Zielinska, G., et al. (2019). Adhesive Protein-Mediated Cross-Talk Between Candida albicans and Porphyromonas gingivalis in Dual Species Biofilm Protects the Anaerobic Bacterium in Unfavorable Oxic Environment. Sci. Rep. 9, 4376. doi: 10.1038/s41598-019-40771-8

Bergeron, A. C., Seman, B. G., Hammond, J. H., Archambault, L. S., Hogan, D. A., and Wheeler, R. T. (2017). Candida albicans and Pseudomonas aeruginosa Interact to Enhance Virulence of Mucosal Infection in Transparent Zebrafish. Infect. Immun. 85, e00475-e00417. doi: 10.1128/IAI.00475-17

Bernard, C., Renaudeau, N., Mollichella, M. -L., Quellard, N., Girardot, M., and Imbert, C. (2018). Cutibacterium acnes Protects Candida albicans From the Effect of Micafungin in Biofilms. Int. J. Antimicrob. Agents 52, 942-946. doi: 10.1016/j.ijantimicag.2018.08.009

Bhardwaj, R. G., Ellepolla, A., Drobiova, H., and Karch ed, M. (2020). Biofilm Growth and IL-8 \& TNF- $\alpha$-Inducing Properties of Candida albicans in the Presence of Oral Gram-Positive and Gram-Negative Bacteria. BMC Microbiol. 20, 156. doi: 10.1186/s12866-020-01834-3

Bonvicini, F., Belluti, F., Bisi, A., Gobbi, S., Manet, I., and Gentilomi, G. A. (2021). Improved Eradication Efficacy of a Combination of Newly Identified Antimicrobial Agents in C. albicans and S. aureus Mixed-Species Biofilm. Res. Microbiol. 172, 103873. doi: 10.1016/j.resmic/2021.103873

Brito, A. C. M., Bezerra, I. M., Borges, M. H. D. S., Cavalcanti, Y. W., and Almeida, L.D.F.D.D. (2021). Effect of Different Salivary Glucose Concentrations on Dual-Species Biofilms of Candida albicans and Streptococcus mutans. Biofouling 37, 615-625. doi: 10.1080/08927014.2021.1946519

Budzyńska, A., Różalska, S., Sadowska, B., and Różalska, B. (2017). Candida albicans/Staphylococcus aureus Dual-Species Biofilm as a Target for the Combination of Essential Oils and Fluconazole or Mupirocin. Mycopathologia 182, 989-995. doi: 10.1007/s11046-017-0192-y

Campbell, M., Fathi, R., Cheng, S. Y., Hom, A., and Gilbertm, E. S. (2020). Rhamnus prinoides (Gesho) Stem Extract Prevents Co-Culture Biofilm Formation by Streptococcus mutans and Candida albicans. Lett. Appl. Microbiol. 71, 294-302. doi: 10.1111/lam.13307

Cavazana, T. P., Hosida, T. Y., Pessan, J. P., Sampaio, C., Monteiro, D. R., and Delbem, A. C. B. (2019). Activity of Sodium Trimetaphosphate, Associated or Not With Fluoride, on Dual-Species Biofilms. Biofouling 35, 710-718. doi: $10.1080 / 08927014.2019 .1653455$

Ceresa, C., Rinaldi, M., Tessarolo, F., Maniglio, D., Fedeli, E., Tambone, E., et al. (2021). Inhibitory Effects of Lipopeptides and Glycolipids on C. albicansStaphylococcus Spp. Dual-Species Biofilms. Front. Microbiol. 11, 3516. doi: $10.3389 /$ fmicb.2020.545654

Černáková, L., Jordao, L., and Bujdáková, H. (2018). Impact of Farnesol and Corsody ${ }^{\circledR}$ on Candida albicans Forming Dual Biofilm With Streptococcus mutans. Oral. Dis. 24 (6), 1126-1131. doi: 10.1111/odi.12873

Cheong, J. Z. A., Johnson, C. J., Wan, H., Liu, A., Kernien, J. F., Gibson, A. L. F., et al. (2021). Priority Effects Dictate Community Structure and Alter Virulence of Fungal-Bacterial Biofilms. ISME J. 15, 2012-2027. doi: 10.1038/s41369-02100901-5

Chevalier, M., Ranque, S., and Prêcheur, I. (2018). Oral Fungal-Bacterial Biofilm Models In Vitro: A Review. Med. Mycol. 56, 653-667. doi: 10.1093/mmy/ myx111

Chinnici, J., Yerke, L., Tsou, C., Busarajan, S., Mancuso, R., Sadhak, N. D., et al. (2019). Candida albicans Cell Wall Integrity Transcription Factors Regulate Polymicrobial Biofilm Formation With Streptococcus gordonii. PeerJ 7, e7870. doi: $10.7717 /$ peerj.7870

Chong, W. X., Lai, Y. X., Choudhury, M., and Amalraj, F. D. (2021). Efficacy of Incorporating Silver Nanoparticles Into Maxillofacial Silicone Against Staphylococcus aureus, Candida albicans, and Polymicrobial Biofilms. J. Prost. Dent. doi: 10.1016/j.prostdent.2021.01.010

Cocco, A. R., Cuevas-Suárez, C. E., Liu, Y., Lund, R. G., Piva, E., and Hwang, G. (2021). Anti-Biofilm Activity of a Novel Pit and Fissure Self-Adhesive Sealant Modified With Metallic Monomers. Biofouling 36, 245-255. doi: 10.1080/ 08927014.2020 .1748603

Costa, D., Girardot, M., Bertaux, J., Verdon, J., and Imbert, C. (2016). Efficacy of Dental Unit Waterlines Disinfectants on a Polymicrobial Biofilm. Water Res. 91, 38-44. doi: 10.1016/j.watres.2015.12.053

Delaney, C., Kean, R., Short, B., Tumelty, M., McLean, W., Nile, C. J., et al. (2018). Fungi at the Scene of the Crime: Innocent Bystanders or Accomplices in Oral
Infections? Curr. Clin. Microbiol. Rep. 5, 190-200. doi: 10.1007/s40588-0180100-3

d'Enfert, C., Kaune, A.-K., Alaban, L.-R., Chakraborty, S., Cole, N., Delavy, M., et al. (2021). The Impact of the Fungus-Host-Microbiota Interplay Upon Candida albicans Infections: Current Knowledge and New Perspectives. FEMS Microbiol. Rev. 45. doi: 10.1093/femsre/fuaa060

Denega, I., d'Enfert, C., and Bachellier-Bassi, S. (2019). Candida albicans Biofilms Are Generally Devoid of Persister Cells. Antimicrob. Agents Chemother. 63, e01979-e01918. doi: 10.1128/AAC.01979-18

Deng, L., Li, W., He, Y., Wu, J., Ren, B., and Zou, L. (2019a). Cross-Kingdom Interaction of Candida albicans and Actinomyces viscosus Elevated Cariogenic Virulence. Arch. Oral. Biol. 100, 106-112. doi: 10.1016/j.archoralbio.2019.02.008

Deng, L., Zou, L., Wu, J., Liu, H., Luo, T., Zhou, X., et al. (2019b). Voriconazole Inhibits Cross-Kingdom Interactions Between Candida albicans and Actinomyces viscosus Through the Ergosterol Pathway. Int. J. Antimicrob. Agents 53, 805-813. doi: 10.1016/j.ijantimicag.2019.02.010

de Oliveira, J. R., de Jesus, D., Figueira, L. W., de Oliveira, F. E., Pacheco Soares, C., Camargo, S. E. A., et al. (2017a). Biological Activities of Rosmarinus officinalis L. (Rosemary) Extract as Analyzed in Microorganisms and Cells. Exp. Biol. Med. 242, 625-634. doi: 10.1177/1535370216688571

de Oliveira, J. R. D., de Jesus Viegas, D., Martins, A. P. R., Carvalho, C. A. T., Soares, C. P., Camargo, S. E. A., et al. (2017b). Thymus vulgaris L. Extract has Antimicrobial and Anti-Inflammatory Effects in the Absence of Cytotoxicity and Genotoxicity. Arch. Oral. Biol. 82, 271-279. doi: 10.1016/ j.archoralbio.2017.06.031

Dhamgaye, S., Qu, Y., and Peleg, A. Y. (2016). Polymicrobial Infections Involving Clinically Relevant Gram-Negative Bacteria and Fungi. Cell. Microbiol. 18, 1716-1722. doi: $10.1111 / \mathrm{cmi} .12674$

Di Fermo, P., Ciociola, T., Di Lodovico, S., D'ercole, S., Petrini, M., Giovati, L., et al. (2021). Antimicrobial Peptide L18R Displays a Modulating Action Against Inter-Kingdom Biofilms in the Lubbock Chronic Wound Biofilm Model. Microorganisms 9, 1779. doi: 10.3390/microorganisms9081779

Du, Q., Ren, B., He, J., Peng, X., Guo, Q., Zheng, L., et al. (2021). Candida albicans Promotes Tooth Decay by Inducing Oral Microbial Dysbiosis. ISME J. 15, 894908. doi: 10.1038/s41396-020-00823-8

Dutton, L. C., Jenkinson, H. F., Lamont, R. J., and Nobbs, A. H. (2016). Role of Candida albicans Secreted Aspartyl Protease Sap9 in Interkingdom Biofilm Formation. Pathog. Dis. 74, ftw005. doi: 10.1093/femspd/ftw005

Eidt, G., Andrade, C. G., Negrini, T. C., and Arthur, R. A. (2019). Role of Candida albicans on Enamel Demineralization and on Acidogenic Potential of Streptococcus mutans In Vitro Biofilms. J. Appl. Oral. Sci. 27, e20180593. doi: 10.1590/1678-7757-2018-0593

Escobar, I. E., Possamai Rossatto, F. C., Kim, S. M., Kang, M. H., Kim, W., and Mylonakis, E. (2021). Repurposing Kinase Inhibitor Bay 11-7085 to Combat Staphylococcus aureus and Candida albicans Biofilms. Front. Pharmacol. 12. doi: $10.3389 /$ fphar.2021.675300

Farrokhi, Y., Al-Shibli, B., Al-Hameedawi, D. F., Neshati, Z., and Makhdoumi, A. (2021). Escherichia coli Enhances the Virulence Factors of Candida albicans, the Cause of Vulvovaginal Candidiasis, in a Dual Bacterial/Fungal Biofilm. Res. Microbiol. 172, 103849. doi: 10.1016/j.resmic.2021.103849

Feldman, M., Ginsburg, I., Al-Quntar, A., and Steinberg, D. (2016). Thiazolidinedione-8 Alters Symbiotic Relationship in C. albicans-S. mutans Dual Species Biofilm. Front. Microbiol. 7. doi: 10.3389/fmicb.2016.00140

Feldman, M., Shenderovich, J., Lavy, E., Friedman, M., and Steinberg, D. (2017). A Sustained-Release Membrane of Thiazolidinedione-8: Effect on Formation of a Candida/bacteria Mixed Biofilm on Hydroxyapatite in a Continuous Flow Model. BioMed. Res. Int. 2017, 1-9. doi: 10.1155/2017/3510124

Fernandes, R. A., Monteiro, D. R., Arias, L. S., Fernandes, G. L., Delbem, A. C. B., and Barbosa, D. B. (2018). Virulence Factors in Candida albicans and Streptococcus mutans Biofilms Mediated by Farnesol. Indian J. Microbiol. 58, 138-145. doi: 10.1007/s12088-018-0714-4

Fernandes, L., Fortes, B. N., Lincopan, N., and Ishida, K. (2020). Caspofungin and Polymyxin B Reduce the Cell Viability and Total Biomass of Mixed Biofilms of Carbapenem-Resistant Pseudomonas aeruginosa and Candida Spp. Front. Microbiol. 11. doi: 10.3389/fmicb.2020.573263

Ferrer-Espada, R., Fang, Y., and Dai, T. (2018). Antimicrobial Blue Light Inactivation of Biofilms Formed by Clinical Isolates of Multidrug-Resistant Microorganisms. Proc. SPIE 10479, 104790N. doi: 10.1117/12.2288520 
Ferrer-Espada, R., Liu, X., Goh, X. S., and Dai, T. (2019). Antimicrobial Blue Light Inactivation of Polymicrobial Biofilms. Front. Microbiol. 10. doi: 10.3389/ fmicb.2019.00721

Filipović, N., Ušjak, D., Milenković, M. T., Zheng, K., Liverani, L., Boccaccini, A. R., et al. (2021). Comparative Study of the Antimicrobial Activity of Selenium Nanoparticles With Different Surface Chemistry and Structure. Front. Bioeng. Biotechnol. 8. doi: 10.3389/fbioe.2020.624621

Fourie, R., Albertyn, J., Sebolai, O., Gcilitshana, O., and Pohl, C. H. (2021). Candida Albicans SET3 Plays a Role in Early Biofilm Formation, Interaction With Pseudomonas aeruginosa and Virulence in Caenorhabditis elegans. Front. Cell. Infect. Microbiol. 11. doi: 10.3389/fcimb.2021.680732

Fourie, R., Ells, R., Kemp, G., Sebolai, O. M., Albertyn, J., and Pohl, C. H. (2017). Pseudomonas aeruginosa Produces Aspirin Insensitive Eicosanoids and Contributes to the Eicosanoid Profile of Polymicrobial Biofilms With Candida albicans. Prostaglandins Leukot. Essent. Fatty Acids 117, 36-46. doi: 10.1016/j.plefa.2017.01.008

Fourie, R., Ells, R., Swart, C. W., Sebolai, O. M., Albertyn, J., and Pohl, C. H. (2016). Candida albicans and Pseudomonas aeruginosa Interaction, With Focus on the Role of Eicosanoids. Front. Physiol. 7, 64. doi: 10.3389/ fphys.2016.00064

Fourie, R., Kuloyo, O. O., Mochochoko, B. M., Albertyn, J., and Pohl, C. H. (2018). Iron at the Centre of Candida albicans Interactions. Front. Cell. Infect. Microbiol. 8, 185. doi: 10.3389/fcimb.2018.00185

Fourie, R., and Pohl, C. H. (2019). Beyond Antagonism: The Interaction Between Candida Species and Pseudomonas aeruginosa. J. Fungi 5, 34. doi: 10.3390/ jof5020034

Fu, Y., Wang, W., Zeng, Q., Wang, T., and Qian, W. (2021). Antibiofilm Efficacy of Luteolin Against Single and Dual Species of Candida albicans and Enterococcus faecalis. Front. Microbiol. 15. doi: 10.3389/fmicb.2021.715156

Gabrilska, R. A., and Rumbaugh, K. P. (2015). Biofilm Models of Polymicrobial Infection. Future Microbiol. 10, 1997-2015. doi: 10.2217/fmb.15.109

Galdiero, E., de Alteriis, E., De Natale, A., D’Alterio, A., Siciliano, A., Guida, M., et al. (2020b). Eradication of Candida albicans Persister Cell Biofilm by the Membranotropic Peptide Gh625. Sci. Rep. 10, 578. doi: 10.1038/s41598-02062746-w

Galdiero, E., Di Onofrio, V., Maione, A., Gambino, E., Gesuele, R., Menale, B., et al. (2020a). Allium ursinum and Allium oschaninii Against Klebsiella pneumoniae and Candida albicans Mono-and Polymicrobic Biofilms in In Vitro Static and Dynamic Models. Microorganisms 8, 336. doi: 10.3390/ microorganisms 8030336

Galdiero, E., Ricciardelli, A., D’Angelo, C., de Alteriis, E., Maione, A., Albarano, L., et al. (2021b). Pentadecanoic Acid Against Candida albicans-Klebsiella pneumoniae Biofilm: Towards the Development of an Anti-Biofilm Coating to Prevent Polymicrobial Infections. Res. Microbiol. 172, 103880. doi: 10.1016/ j.resmic.2021.103880

Galdiero, E., Salvatore, M. M., Maione, A., Carraturo, F., Galdiero, S., Falanga, A., et al. (2021a). Impact of the Peptide Wmr-K on Dual-Species Biofilm Candida albicans/Klebsiella pneumoniae and on the Untargeted Metabolomic Profile. Pathogens 10, 214. doi: 10.3390/pathogens10020214

Gao, Y., Jiang, X., Lin, D., Chen, Y., and Tong, Z. (2016). The Starvation Resistance and Biofilm Formation of Enterococcus faecalis in Coexistence With Candida albicans, Streptococcus gordonii, Actinomyces viscosus, or Lactobacillus acidophilus. J. Endod. 42 (8), 1233-1238. doi: 10.1016/j.joen.2016.05.002

Gao, S., Liu, G., Li, J., Chen, J., Li, L., Li, Z., et al. (2020). Antimicrobial Activity of Lemongrass Essential Oil (Cymbopogon flexuosus) and Its Active Component Citral Against Dual-Species Biofilms of Staphylococcus aureus and Candida Species. Front. Cell. Infect. Microbiol. 10. doi: 10.3389/fcimb.2020.603858

Gao, S., Zhang, S., and Zhang, S. (2021). Enhanced In Vitro Antimicrobial Activity of Amphotericin B With Berberine Against Dual-Species Biofilms of Candida albicans and Staphylococcus aureus. J. Appl. Microbiol. 130, 1154-1172. doi: $10.1111 /$ jam.14872

Garcia, L. M., Costa-Orlandi, C. B., Bila, N. M., Vaso, C. O., Gonçalves, L. N. C., Fusco-Almeida, A. M., et al. (2020). A Two-Way Road: Antagonistic Interaction Between Dual-Species Biofilms Formed by Candida albicans/ Candida parapsilosis and Trichophyton rubrum. Front. Microbiol. 11. doi: $10.3389 /$ fmicb.2020.01980

Garipov, M. R., Sabirova, A. E., Pavelyev, R. S., Shtyrlin, N. V., Lisovskaya, S. A., Bondar, O. V., et al. (2020). Targeting Pathogenic Fungi, Bacteria and Fungal-
Bacterial Biofilms by Newly Synthesized Quaternary Ammonium Derivative of Pyridoxine and Terbinafine With Dual Action Profile. Bioorg. Chem. 104, 104306. doi: 10.1016/j.bioorg.2020.104306

Gaston, J. R., Johnson, A. O., Bair, K. L., White, A. N., and Armbruster, C. E. (2021). Polymicrobial Interactions in the Urinary Tract: Is the Enemy of My Enemy My Friend? Infect. Immun. 89, e00652-e00620. doi: 10.1128/IAI.00652-20

Gong, J., Hu, D., He, J., Zou, L., Chen, Z., and Li, M. (2021). Effect of LongZhang Gargle on Dual-Species Biofilm of Candida albicans and Streptococcus mutans. BioMed. Res. Internat. 2021, 6654793. doi: 10.1155/2021/6654793

Guo, H., Chen, Y., Guo, W., and Chen, J. (2020). Heme Competition Triggers an Increase in the Pathogenic Potential of Porphyromonas gingivalis in Porphyromonas gingivalis-Candida albicans Mixed Biofilm. Front. Microbiol. 11. doi: $10.3389 /$ fmicb. 2020.596459

Guo, H., Chen, Y., Guo, W., and Chen, J. (2021). Effects of Extracellular DNA on Dual-Species Biofilm Formed by Streptococcus mutans and Candida albicans. Microb. Pathog. 154, 104838. doi: 10.1016/j.micpath.2021.104838

Gupta, S., Thakur, J., Pal, S., Gupta, R., Mishra, D., Kumar, S., et al. (2019). Cholic Acid-Peptide Conjugates as Potent Antimicrobials Against Interkingdom Polymicrobial Biofilms. Antimicrob. Agents Chemother. 63, e00520-e00519. doi: 10.1128/AAC.00520-19

Hamzah, H., Hertiani, T., Pratiwi, S. U. T., and Nuryastuti, T. (2020a). Inhibitory Activity and Degradation of Curcumin as Anti-Biofilm Polymicrobial on Catheters. Int. J. Res. Pharm. Sci. 11, 830-835. doi: 10.26452/ijrps.v11i1.190

Hamzah, H., Hertiani, T., Pratiwi, S. U. T., and Nuryastuti, T. (2020b). Efficacy of Quercetin Against Polymicrobial Biofilm on Catheters. Res. J. Pharm. Technol. 13, 5277-5282. doi: 10.5958/0974-360X.2020.00923.3

Hamzah, H., Hertiani, T., Pratiwi, S. U. T., Nuryastuti, T., and Gani, A. P. (2020c). Antibiofilm Studies of Zerumbone Against Polymicrobial Biofilms of Staphylococcus aureus, Escherichia coli, Pseudomonas aeruginosa, and Candida albicans. Int. J. Pharm. Res. 2020 (suppl 1), 1307-1314. doi: $10.31838 / \mathrm{ijpr} / 2020 . S P 1.211$

He, J., Kim, D., Zhou, X., Ahn, S.-J., Burne, R. A., Richards, V. P., et al. (2017). RNA-Seq Reveals Enhanced Sugar Metabolism in Streptococcus mutans CoCultured With Candida albicans Within Mixed-Species Biofilms. Front. Microbiol. 8. doi: 10.3389/fmicb.2017.01036

Herman-Bausier, P., Labate, C., Towell, A. M., Derclaye, S., Geoghegan, J. A., and Dufrêne, Y. F. (2018). Staphylococcus aureus Clumping Factor A Is a ForceSensitive Molecular Switch That Activates Bacterial Adhesion. Proc. Natl. Acad. Sci. 115, 5564-5569. doi: 10.1073/pnas.1718104115

Holt, J. E., Houston, A., Adams, C., Edwards, S., and Kjellerup, B. V. (2017). Role of Extracellular Polymeric Substances in Polymicrobial Biofilm Infections of Staphylococcus epidermidis and Candida albicans Modelled in the Nematode Caenorhabditis elegans. Pathog. Dis. 31, ftx052. doi: 10.1093/femspd/ftx052

Huffines, J. T., and Scoffield, J. A. (2020). Disruption of Streptococcus mutans and Candida albicans Synergy by a Commensal Streptococcus. Sci. Rep. 10, 1966. doi: 10.1038/s41598-020-76744-5

Hu, Y., Niu, Y., Ye, X., Zhu, C., Tong, T., Zhou, Y., et al. (2021). Staphylococcus aureus Synergized With Candida albicans to Increase the Pathogenesis and Drug Resistance in Cutaneous Abscess and Peritonitis Murine Models. Pathogens 10, 1036. doi: 10.3390/pathogens10081036

Ikono, R., Vibriani, A., Wibowo, I., Saputro, K. E., Muliawan, W., Bachtiar, B. M., et al. (2019). Nanochitosan Antimicrobial Activity Against Streptococcus mutans and Candida albicans Dual-Species Biofilms. BMC Res. Notes 12, 383. doi: 10.1186/s13104-019-4422-x

Jakubovics, N. S. (2017). The Sixth Sensor: A Candida albicans Biofilm Master Regulator That Responds to Inter-Kingdom Interactions. Virulence 8, 14651467. doi: $10.1080 / 21505594.2017 .1353864$

Janus, M. M., Crielaard, W., Volgenant, C. M. C., der Veen, M. H. V., Brandt, B. W., and Krom, B. P. (2017). Candida albicans Alters the Bacterial Microbiome of Early In Vitro Oral Biofilms. J. Oral. Microbiol. 9, 1270613. doi: 10.1080/ 20002297.2016.1270613

Jesionowski, A. M., Mansfield, J. M., Brittan, J. L., Jenkinson, H. F., and Vickerman, M. M. (2016). Transcriptome Analysis of Streptococcus gordonii Challis DL1 Indicates a Role for the Biofilm-Associated fruRBA Operon in Response to Candida albicans. Mol. Oral. Microbiol. 31, 314-328. doi: 10.1111/ omi. 12125

Kanugala, S., Jinka, S., Puvvada, N., Banerjee, R., and Kumar, C. G. (2019). Phenazine-1-Carboxamide Functionalized Mesoporous Silica Nanoparticles as 
Antimicrobial Coatings on Silicone Urethral Catheters. Sci. Rep. 9, 6198. doi: 10.1038/s41598-019-42722-9

Karkowska-Kuleta, J., Bartnicka, D., Zawrotniak, M., Zielinska, G., Kierońska, A., Bochenska, O., et al. (2018). The Activity of Bacterial Peptidylarginine Deiminase Is Important During Formation of Dual-Species Biofilm by Periodontal Pathogen Porphyromonas gingivalis and Opportunistic Fungus Candida albicans. Pathog. Dis. 76, fty033. doi: 10.1093/femspd/fty033

Kasetty, S., Mould, D. L., Hogan, D. A., and Nadell, C. D. (2021). Both Pseudomonas aeruginosa and Candida albicans Accumulate Greater Biomass in Dual-Species Biofilms Under Flow. mSphere 6, e0041621. doi: 10.1128/ mSphere.00416-21

Kean, R., Rajendran, R., Haggarty, J., Townsend, E. M., Short, B., Burgess, K. E., et al. (2017). Candida albicans Mycofilms Support Staphylococcus aureus Colonization and Enhances Miconazole Resistance in Dual-Species Interactions. Front. Microbiol. 8. doi: 10.3389/fmicb.2017.00258

Khan, F., Bamunuarachchi, N. I., Nguyen, D. T., Tabassum, P. N., Khan, M. S. A., and Kim, Y. (2021). Mixed Biofilms of Pathogenic Candida-Bacteria: Regulation Mechanisms and Treatment Strategies. Crit. Rev. Microbiol. 47, 699-727. doi: 10.1080/1040841X.2021.1921696

Kim, D., and Koo, H. (2020). Spatial Design of Polymicrobial Oral Biofilm in its Native Disease State. J. Dent. Res. 99, 597-603. doi: 10.1177/0022034520909313

Kim, D., Liu, Y., Benhamou, R. I., Sanchez, H., Simón-Soro, Á., Li, Y., et al. (2018). Bacterial-Derived Exopolysaccharides Enhance Antifungal Drug Tolerance in a Cross-Kingdom Oral Biofilm. ISME J. 12, 1427-1442. doi: 10.1038/s41396018-0113-1

Kim, Y. -G., Lee, J. -H., Park, S., Kim, S., and Lee, J. (2021). Inhibition of Polymicrobial Biofilm Formation by Saw Palmetto Oil, Lauric Acid and Myristic Acid. Microb. Biotechnol. doi: 10.1111/1751-7915.13864

Kong, E. F., Tsui, C., Kucharíková, S., Andes, D., Van Dijck, P., and Jabra-Rizk, M. A. (2016). Commensal Protection of Staphylococcus aureus Against Antimicrobials by Candida albicans Biofilm Matrix. mBio 11, e01365-16. doi: $10.1128 / \mathrm{mBio} .01365-16$

Kong, E. F., Tsui, C., Kucharíková, S., Van Dijck, P., and Jabra-Rizk, M. A. (2017). Modulation of Staphylococcus aureus Response to Antimicrobials by the Candida albicans Quorum Sensing Molecule Farnesol. Antimicrob. Agents Chemother. 61, e01573-17. doi: 10.1128/AAC.01573-17

Krishnamoorthy, A. L., Lemus, A. A., Solomon, A. P., Valm, A. M., and Neelakantan, P. (2020). Interactions Between Candida albicans and Enterococcus faecalis in an Organotypic Oral Epithelial Model. Microorganisms 8, 1771. doi: 10.3390/microorganisms8111771

Krüger, W., Vielreicher, S., Kapitan, M., Jacobsen, I. D., and Niemiec, M. J. (2019). Fungal-Bacterial Interactions in Health and Disease. Pathogens 8, 70. doi: $10.3390 /$ pathogens 8020070

Lara, H. H., and Lopez-Ribot, J. L. (2020). Inhibition of Mixed Biofilms of Candida albicans and Methicillin-Resistant Staphylococcus aureus by Positively Charged Silver Nanoparticles and Functionalized Silicone Elastomers. Pathogens 25, 784. doi: 10.3390/pathogens 9100784

Lee, J.-H., Kim, Y.-G., Khadke, S. K., Yamano, A., Watanabe, A., and Lee, J. (2019). Inhibition of Biofilm Formation by Candida albicans and Polymicrobial Microorganisms by Nepodin via Hyphal-Growth Suppression. ACS Infect. Dis. 5, 1177-1187. doi: 10.1021/acsinfecdis.9b0033

Little, W., Black, C., and Smith, A. C. (2021). Clinical Implications of Polymicrobial Synergism Effects on Antimicrobial Susceptibility. Pathogens 10, 144. doi: $10.3390 /$ pathogens 10020144

Liu, S., Qiu, W., Zhang, K., Zhou, X., Ren, B., He, J., et al. (2017). Nicotine Enhances Interspecies Relationship Between Streptococcus mutans and Candida albicans. BioMed. Res. Int. 2017, 7953920. doi: 10.1155/2017/7953920

Li, X., Yin, L., Ramage, G., Li, B., Tao, Y., Zhi, Q., et al. (2019). Assessing the Impact of Curcumin on Dual-Species Biofilms Formed by Streptococcus mutans and Candida albicans. MicrobiologyOpen 8, e937. doi: 10.1002/ mbo3.937

Lobo, C. I. V., Lopes, A. C. U. A., and Klein, M. I. (2021). Compounds With Distinct Targets Present Diverse Antimicrobial and Antibiofilm Efficacy Against Candida albicans and Streptococcus mutans, and Combinations of Compounds Potentiate Their Effect. J. Fungi 7, 340. doi: 10.3390/jof7050340

Lobo, C. I. V., Rinaldi, T. B., Christiano, C. M. S., De Sales Leite, L., Barbugli, P. A., and Klein, M. I. (2019). Dual-Species Biofilms of Streptococcus mutans and Candida albicans Exhibit More Biomass and Are Mutually Beneficial
Compared With Single-Species Biofilms. J. Oral. Microbiol. 11, 1581520. doi: 10.1080/20002297.2019.1581520

Luo, Y., Bolt, H. L., Eggimann, G. A., McAuley, D. F., McMullan, R., Curran, T., et al. (2017). Peptoid Efficacy Against Polymicrobial Biofilms Determined by Using Propidium Monoazide-Modified Quantitative PCR. Chembiochem 18, 111-118. doi: 10.1002/cbic.201600381

Luo, Y., McAuley, D. F., Fulton, C. R., Pessoa, J. S., McMullan, R., and Lundy, F. T. (2021). Targeting Candida albicans in Dual-Species Biofilms With Antifungal Treatment Reduces Staphylococcus aureus and MRSA In Vitro. PloS One 16, e0249547. doi: 10.1371/journal.pone.0249547

Maione, A., de Alteriis, E., Carraturo, F., Galdiero, S., Falanga, A., Guida, M., et al. (2021). The Membranotropic Peptide Gh625 to Combat Mixed Candida albicans/Klebsiella pneumoniae Biofilm: Correlation Between In Vitro AntiBiofilm Activity and In Vivo Antimicrobial Protection. J. Fungi 7, 26. doi: $10.3390 /$ jof7010026

Maisetta, G., and Batoni, G. (2020). Editorial: Interspecies Interactions: Effects on Virulence and Antimicrobial Susceptibility of Bacterial and Fungal Pathogens. Front. Microbiol. 11. doi: 10.3389/fmicb.2020.01922

Ma, S., Moser, D., Han, F., Leonhard, M., Schneider-Stickler, B., and Tan, Y. (2020). Preparation and Antibiofilm Studies of Curcumin Loaded Chitosan Nanoparticles Against Polymicrobial Biofilms of Candida albicans and Staphylococcus aureus. Carbohydr. Polym. 241, 116254. doi: 10.1016/ j.carbpol.2020.116254

Mazaheritehrani, E., Sala, A., Orsi, C. F., Neglia, R. G., Morace, G., Blasi, E., et al. (2014). Human Pathogenic Viruses Are Retained in and Released by Candida albicans Biofilm In Vitro. Virus Res. 179, 153-160. doi: 10.1016/j.virusres.2013.10.018

Mgomi, F. C., Yuan, L., Chen, C. W., Zhang, Y. S., and Yang, Z. Q. (2021). Bacteriophages: A Weapon Against Mixed-Species Biofilms in the Food Processing Environment. J. Appl. Microbiol. doi: 10.1111/jam.15421

Mieher, J. L., Schormann, N., Wu, R., Patel, M., Purushotham, S., Wu, H., et al. (2021). Structure-Function Characterization of Streptococcus intermedius Surface Antigen Pas. J. Bacteriol. 203, e00175-21. doi: 10.1128/JB.00175-21

Mochochoko, B. M., Ezeokoli, O. T., Sebolai, O., Albertyn, J., and Pohl, C. H. (2021). Role of the High-Affinity Reductive Iron Acquisition Pathway of Candida albicans in Prostaglandin $\mathrm{E}_{2}$ Production, Virulence, and Interaction With Pseudomonas aeruginosa. Med. Mycol. 3, 869-881. doi: 10.1093/mmy/myab015

Montelongo-Jauregui, D., Saville, S. P., and Lopez-Ribot, J. L. (2019). Contributions of Candida albicans Dimorphism, Adhesive Interactions, and Extracellular Matrix to the Formation of Dual-Species Biofilms With Streptococcus gordonii. mBio 10, e01179-e01119. doi: 10.1128/mBio.01179-19

Montelongo-Jauregui, D., Srinivasan, A., Ramasubramanian, A. K., and LopezRibot, J. L. (2016). An In Vitro Model for Oral Mixed Biofilms of Candida albicans and Streptococcus gordonii in Synthetic Saliva. Front. Microbiol. 12 (7). doi: $10.3389 /$ fmicb.2016.00686

Montelongo-Jauregui, D., Srinivasan, A., Ramasubramanian, A. K., and LopezRibot, J. L. (2018). An In Vitro Model for Candida albicans-Streptococcus gordonii Biofilms on Titanium Surfaces. J. Fungi 4, 66. doi: 10.3390/jof4020066

Morse, D. J., Wilson, M. J., Wei, X., Bradshaw, D. J., Lewis, M. A. O., and Williams, D. W. (2019). Modulation of Candida albicans Virulence in In Vitro Biofilms by Oral Bacteria. Lett. Appl. Microbiol. 68, 337-343. doi: 10.1111/lam.13145

Morse, D. J., Wilson, M. J., Wei, X., Lewis, M. A. O., Bradshaw, D. J., Murdoch, C., et al. (2018). Denture-Associated Biofilm Infection in Three-Dimensional Oral Mucosal Tissue Models. J. Med. Microbiol. 67, 364-375. doi: 10.1099/ jmm.0.000677

Mukherjee, S., Barman, S., Mukherjee, R., and Haldar, J. (2020). Amphiphilic Cationic Macromolecules Highly Effective Against Multi-Drug Resistant Gram-Positive Bacteria and Fungi With No Detectable Resistance. Front. Bioeng. Biotechnol. 8. doi: 10.3389/fbioe.2020.00055

Nabb, D. L., Song, S., Kluthe, K. E., Daubert, T. A., Luedtke, B. E., and Nuxoll, A. S. (2019). Polymicrobial Interactions Induce Multidrug Tolerance in Staphylococcus aureus Through Energy Depletion. Front. Microbiol. 10. doi: $10.3389 /$ fmicb.2019.02803

Naglik, J. R., Gaffen, S. L., and Hube, B. (2019). Candidalysin: Discovery and Function in Infections. Curr. Opin. Microbiol. 52, 100-109. doi: 10.1016/ j.mib.2019.06.002

Nazik, H., Joubert, L. M., Secor, P. R., Sweere, J. M., Bollyky, P. L., Sass, G., et al. (2017). Pseudomonas Phage Inhibition of Candida albicans. Microbiology 163, 1568-1577. doi: 10.1099/mic.0.000539 
Negrini, T. C., Koo, H., and Arthu, R. R. A. (2019). Candida-Bacterial Biofilms and Host-Microbe Interactions in Oral Diseases. Adv. Exp. Med. Biol. 1197, 119141. doi: 10.1007/978-3-030-28524-1_10

Orazi, G., and O’Toole, G. A. (2019). It Takes a Village”: Mechanisms Underlying Antimicrobial Recalcitrance of Polymicrobial Biofilms. J. Bacteriol. 202, e00530-e00519. doi: 10.1128/JB.00530-19

Palencia, S. L., García, A., and Palencia, M. (2022). Multiple Surface Interaction Mechanisms Direct the Anchoring, Co-Aggregation and Formation of DualSpecies Biofilm Between Candida albicans and Helicobacter pylori. J. Adv. Res. 35, 169-185. doi: 10.1016/j.jare.2021.03.013

Pathirana, R. U., McCall, A. D., Norris, H. L., and Edgerton, M. (2019). Filamentous non-Albicans candida Species Adhere to Candida albicans and Benefit From Dual Biofilm Growth. Front. Microbiol. 10. doi: 10.3389/ fmicb.2019.01188

Peng, H., Zhang, P., Bilal, M., Wang, W., Hu, H., and Zhang, X. (2018). Enhanced Biosynthesis of Phenazine-1-Carboxamide by Engineered Pseudomonas chlororaphis HT66. Microb. Cell Fact. 17, 117. doi: 10.1186/s12934-0180962-3

Philip, N., Leishman, S. J., Bandara, H., and Walsh, L. J. (2019). Polyphenol-Rich Cranberry Extracts Modulate Virulence of Streptococcus mutans-Candida albicans Biofilms Implicated in the Pathogenesis of Early Childhood Caries. Pediatr. Dent. 41, 56-62.

Prabha, S., Sowndarya, J., Ram, P. J. V. S., Rubini, D., Hari, B. N. V., Aruni, W., et al. (2021). Chitosan-Coated Surgical Sutures Prevent Adherence and Biofilms of Mixed Microbial Communities. Curr. Microbiol. 78, 502-512. doi: $10.10 .1007 / \mathrm{s} 00284-020-02306-7$

Pratiwi, S. U. T., and Hamzah, H. (2020). Inhibition and Degradation Activity of (Sapindus rarak Seeds) Ethanol Extract Against Polymicrobial Biofilm. Res. J. Pharm. Tech. 13, 5425-5430. doi: 10.5958/0974-360X.2020.00947.6

Qu, Y., Locock, K., Verma-Gaur, J., Hay, I. D., Meagher, L., and Traven, A. (2016). Searching for New Strategies Against Polymicrobial Biofilm Infections: Guanylated Polymethacrylates Kill Mixed Fungal/Bacterial Biofilms. J. Antimicrob. Chemother. 71, 413-421. doi: 10.1093/jac/dkv334

Rocha, G. R., Florez Salamanca, E. J., de Barros, A. L., Lobo, C. I. V., and Klein, M. I. (2018). Effect of Tt-Farnesol and Myricetin on In Vitro Biofilm Formed by Streptococcus mutans and Candida albicans. BMC Comp. Alt. Med. 18, 61. doi: 10.1186/s12906-018-2132-

Rodrigues, M. E., Lopes, S. P., Pereira, C. R., Azevedo, N. F., Lourenço, A., Henriques, M., et al. (2017). Polymicrobial Ventilator-Associated Pneumonia: Fighting In Vitro Candida albicans-Pseudomonas aeruginosa Biofilms With Antifungal-Antibacterial Combination Therapy. PloS One 12, e0170433. doi: 10.1371/journal.pone.017043

Rogiers, O., Holtappels, M., Siala, W., Lamkanfi, M., Van Bambeke, F., Lagrou, K., et al. (2018). Anidulafungin Increases the Antibacterial Activity of Tigecycline in Polymicrobial Candida albicans/Staphylococcus aureus Biofilms on Intraperitoneally Implanted Foreign Bodies. J. Antimicrob. Chemother. 73, 2806-2814. doi: 10.1093/jac/dky246

Rossoni, R. D., Barbosa, J. O., Vilela, S. F. G., dos Santos, J. D., de Barros, P. P., Prata de Avezo, M. C., et al. (2015). Competitive Interactions Between C. albicans, C. glabrata and C. krusei During Biofilm Formation and Development of Experimental Candidiasis. PloS One 10, e0131700. doi: 10.1371/journal.pone.0131700

Rubini, D., Vedha Hari, B. N., and Nithyanand, P. (2021). Chitosan Coated Catheters Alleviates Mixed Species Biofilms of Staphylococcus epidermidis and Candida albicans. Carbohydr. Polym. 15, 117192. doi: 10.1016/ j.carbpol.2020.117192

Ruiz-Sorribas, A., Poilvache, H., Kamarudin, N. H. N., Braem, A., and Van Bambeke, F. (2021). In Vitro Polymicrobial Inter-Kingdom Three-Species Biofilm Model: Influence of Hyphae on Biofilm Formation and Bacterial Physiology. Biofouling 37, 481-493. doi: 10.1080/08927014.2021.1919301

Sampaio, A. A., Souza, S. E., Ricomini-Filho, A. P., Del Bel Cury, A. A., Cavalcanti, Y. W., and Cury, J. A. (2019). Candida albicans Increases Dentine Demineralization Provoked by Streptococcus mutans Biofilm. Caries Res. 53, 322-331. doi: 10.1159/000494033

She, P., Liu, Y., Wang, Y., Tan, F., Luo, Z., and Wu, Y. (2020). Antibiofilm Efficacy of the Gold Compound Auranofin on Dual Species Biofilms of Staphylococcus aureus and Candida Sp. J. Appl. Microbiol. 128, 88-101. doi: 10.1111/ jam.14443
Shin, D.-S., and Eom, Y.-B. (2019). Efficacy of Zerumbone Against Dual-Species Biofilms of Candida albicans and Staphylococcus aureus. Microb. Pathog. 137, 103768. doi: 10.1016/j.micpath.2019.103768

Souza, J. G. S., Bertolini, M., Thompson, A., Barão, V. A. R., and DongariBagtzoglou, A. (2020b). Biofilm Interactions of Candida albicans and Mitis Group Streptococci in a Titanium-Mucosal Interface Model. Appl. Environ. Microbiol. 86, e02950-e02919. doi: 10.1128/AEM.02950-19

Souza, J. G. S., Bertolini, M., Thompson, A., Mansfield, J. M., Grassmann, A. A., Maas, K., et al. (2020a). Role of Glucosyltransferase R in Biofilm Interactions Between Streptococcus oralis and Candida albicans. ISME J. 14, 1207-1222. doi: 10.1038/s41396-020-0608-4

Srikanth, R., Banu, S. F., Sowndarya, J., Parveen, J. H. S., Rubini, D., Wilson, A., et al. (2021). Biosurfactant Synergized With Marine Bacterial DNase Disrupts Polymicrobial Biofilms. Folia Microbiol. 66, 831-842. doi: 10.1007/s12223-02100876-y

Srinivasan, A., Torres, N. S., Leung, K. P., Lopez-Ribot, J. L., and Ramasubramanian, A. K. (2017). Nbiochip, a Lab-on-a-Chip Platform of Mono and Polymicrobial Biofilms for Highthroughput Downstream Applications. mSphere 2, e00247-e00217. doi: 10.1128/mSphere.00247-17

Stoffel, J. J., Kohler Riedi, P. L., and Hadj Romdhane, B. (2020). A Multimodel Regime for Evaluating Effectiveness of Antimicrobial Wound Care Products in Microbial Biofilms. Wound Repair Regen. 28, 438-447. doi: 10.1111/wrr.12806

Swetha, T. K., Subramenium, G. A., Kasthuri, T., Sharumathi, R., and Pandian, S. K. (2021). 5-Hydroxymethyl-2-Furaldehyde Impairs Candida albicans Staphylococcus epidermidis Interaction in Co-Culture by Suppressing Crucial Supportive Virulence Traits. Microb. Path. 158, 104990. doi: 10.1016/ j.micpath.2021.104990

Szafrański, S. P., Winkel, A., and Stiesch, M. (2017). The Use of Bacteriophages to Biocontrol Oral Biofilms. J. Biotechnol. 250, 29-44. doi: 10.1016/ j.jbiotec.2017.01.002

Sztukowska, M. N., Dutton, L. C., Delaney, C., Ramsdale, M., Ramage, G., Jenkinson, H. F., et al. (2018). Community Development Between Porphyromonas gingivalis and Candida albicans Mediated by inIJ and Als3. mBio 9, e00202-e00218. doi: 10.1128/mBio.00202-18

Tan, Y., Leonhard, M., Moser, D., Ma, S., and Schneider-Stickler, B. (2016). LongTerm Antibiofilm Activity of Carboxymethyl Chitosan on Mixed Biofilm on Silicone. Laryngoscope 126, E404-E408. doi: 10.1002/lary.26096

Tan, Y., Leonhard, M., Moser, D., Ma, S., and Schneider-Stickler, B. (2019). Antibiofilm Efficacy of Curcumin in Combination With 2Aminobenzimidazole Against Single- and Mixed-Species Biofilms of Candida albicans and Staphylococcus aureus. Colloids Surf. B Biointerfaces. 174, 28-34. doi: 10.1016/j.colsurfb.2018.10.079

Tan, Y., Ma, S., Leonhard, M., Moser, D., Ludwig, R., and Schneider-Stickler, B. (2020). Co-Immobilization of Cellobiose Dehydrogenase and Deoxyribonuclease I on Chitosan Nanoparticles Against Fungal/Bacterial Polymicrobial Biofilms Targeting Both Biofilm Matrix and Microorganisms. Mater. Sci. Eng. C Mater. Biol. Appl. 108, 110499. doi: 10.1016/ j.msec.2019.110499

Toral, F. C., Hernández, L. D., González, C. E., Varona, F. S., Ciodaro, A. R., and Ortega, H. D. (2017). Ex Vivo Model for Studying Polymicrobial Biofilm Formation in Root Canals. Univ. Sci. 22, 31-43. doi: 10.11144/javeriana.sc221.evmf

Townsend, E. M., Sherry, L., Kean, R., Hansom, D., Mackay, W. G., Williams, C., et al. (2017). Implications of Antimicrobial Combinations in Complex Wound Biofilms Containing Fungi. Antimicrob. Agents Chemother. 61, e00672e00617. doi: 10.1128/AAC.00672-17

Townsend, E. M., Sherry, L., Rajendran, R., Hansom, D., Butcher, J., Mackay, W. G., et al. (2016). Development and Characterisation of a Novel ThreeDimensional Inter-Kingdom Wound Biofilm Model. Biofouling 32, 12591270. doi: $10.1080 / 08927014.2016 .1252337$

Trejo-Hernández, A., Andrade-Domínguez, A., Hernández, M., and Encarnación, S. (2014). Interspecies Competition Triggers Virulence and Mutability in Candida albicans-Pseudomonas aeruginosa Mixed Biofilms. ISME J. 8, 19741988. doi: 10.1038 /ismej.2014.53

Tsui, C., Kong, E. F., and Jabra-Rizk, M. A. (2016). Pathogenesis of Candida albicans Biofilms. Pathog. Dis. 74, ftw018. doi: 10.1093/femspd/ftw018

Tsutsumi-Arai, C., Arai, Y., Terada-Ito, C., Imamura, T., Tatehara, S., Ide, S., et al. (2021). Microbicidal Effect of 405-Nm Blue LED Light on Candida albicans 
and Streptococcus mutans Dual-Species Biofilms on Denture Base Resin. Lasers Med. Sci. doi: 10.1007/s10103-021-03323-z

Van Dyck, K., Viela, F., Mathelié-Guinlet, M., Demuyser, L., Hauben, E., Jabra-Rizk, M. A., et al. (2021). Adhesion of Staphylococcus aureus to Candida albicans During CoInfection Promotes Bacterial Dissemination Through the Host Immune Response. Front. Cell. Infect. Microbiol. 10. doi: 10.3389/fcimb.2020.624839

Veerapandian, R., and Vediyappan, G. (2019). Gymnemic Acids Inhibit Adhesive Nanofibrillar Mediated Streptococcus gordonii-Candida albicans Mono-Species and Dual-Species Biofilms. Front. Microbiol. 10. doi: 10.3389/ fmicb.2019.02328

Vieira, A. P. M., Arias, L. S., de Souza Neto, F. N., Kubo, A. M., Lima, B. H. R., de Camargo, E. R., et al. (2019). Antibiofilm Effect of Chlorhexidine-Carrier Nanosystem Based on Iron Oxide Magnetic Nanoparticles and Chitosan. Colloids Surf. B Biointerfaces 174, 224-231. doi: 10.1016/j.colsurfb.2018.11.023

Vila, T., Kong, E. F., Montelongo-Jauregui, D., Van Dijck, P., Shetty, A. C., McCracken, C., et al. (2021). Therapeutic Implications of C. albicans-S. aureus Mixed Biofilm in a Murine Subcutaneous Catheter Model of Polymicrobial Infection. Virulence 12, 835-851. doi: 10.1080/21505594.2021.1894834

Wan, S. X., Tian, J., Liu, Y., Dhall, A., Koo, H., and Hwang, G. (2021). CrossKingdom Cell-to-Cell Interactions in Cariogenic Biofilm Initiation. J. Dent. Res. 100, 74-81. doi: 10.1177/0022034520950286

Wijaya, C. H., Septiana, S., Bachtiar, B. M., and Yuliana, N. D. (2019). Cajuputs Candy Impairs Candida albicans and Streptococcus mutans Mixed Biofilm Formation In Vitro. F1000Research 8, 1923. doi: 10.12688/f1000research.20700

Willems, H. M., Kos, K., Jabra-Rizk, M. A., and Krom, B. P. (2016). Candida albicans in Oral Biofilms Could Prevent Caries. Pathog. Dis. 74, ftw039. doi: 10.1093/femspd/ftw039

Xu, H., Sobue, T., Bertolini, M., Thompson, A., Vickerman, M., Nobile, C. J., et al. (2017). S. oralis Activates the Efg1 Filamentation Pathway in C. albicans to Promote Cross-Kingdom Interactions and Mucosal Biofilms. Virulence 8, 1602-1617. doi: 10.1080/21505594.2017.1326438
Yang, C., Scoffield, J., Wu, R., Deivanayagam, C., Zou, J., and Wu, H. (2018). Antigen I/II Mediates Interactions Between Streptococcus mutans and Candida albicans. Mol. Oral. Microbiol. 33, 283-291. doi: 10.1111/omi.12223

Yasinta, M. S., Ginawati, H. L., Arum, N. A., Hikmah, H. N., Sumarsih, S., Fahmi, M. Z., et al. (2021). Dual Function of Silver Nanoparticles as Matrix Extracell Removal and Antimicrobial Agent in Polymycrobial Biofilms. Indones. J. Chem. 21, 286-295. doi: 10.22146/ijc.52355

Yassin, S. A., German, M. J., Rolland, S. L., Rickard, A. H., and Jakubovics, N. S. (2016). Inhibition of Multispecies Biofilms by a Fluoride-Releasing Dental Prosthesis Copolymer. J. Dent. 48, 62-70. doi: 10.1016/j.jdent.2016.03.001

Young, T., Alshanta, O.-A., Kean, R., Bradshaw, D., Pratten, J., Williams, C., et al. (2021). Candida albicans as an Essential "Keystone" Component Within Polymicrobial Oral Biofilm Models? Microorganisms 28, 59. doi: 10.3390/ microorganisms 9010059

Conflict of Interest: The author declares that the research was conducted in the absence of any commercial or financial relationships that could be construed as a potential conflict of interest.

Publisher's Note: All claims expressed in this article are solely those of the authors and do not necessarily represent those of their affiliated organizations, or those of the publisher, the editors and the reviewers. Any product that may be evaluated in this article, or claim that may be made by its manufacturer, is not guaranteed or endorsed by the publisher.

Copyright $\odot 2022$ Pohl. This is an open-access article distributed under the terms of the Creative Commons Attribution License (CC BY). The use, distribution or reproduction in other forums is permitted, provided the original author(s) and the copyright owner(s) are credited and that the original publication in this journal is cited, in accordance with accepted academic practice. No use, distribution or reproduction is permitted which does not comply with these terms. 